\title{
A new analytical model for predicting the radio-thermal oxidation kinetics and the lifetime of electric cable insulation in nuclear power plants. application to silane cross-linked polyethylene
}

\author{
Sarah Hettal ${ }^{\mathrm{a}}$, Sébastien Roland ${ }^{\mathrm{a}}$, Konsta Sipila ${ }^{\mathrm{b}}$, Harri Joki ${ }^{\mathrm{b}}$, Xavier Colin ${ }^{\mathrm{a}, *}$ \\ a PIMM, Arts et Métiers Institute of Technology, CNRS, CNAM, HESAM University, 151 boulevard de l'Hôpital, 75013 Paris, France \\ ${ }^{\mathrm{b}}$ VTT Technical Research Centre of Finland Ltd, P.O. Box 1000, FIN-02044 VTT, Espoo, Finland
}

Keywords:

Silane cross-linked polyethylene

Radio-thermal oxidation

Analytical kinetic model

Hydroperoxide decomposition

Carbonyl build-up

Chain scissions

Structural end-of-life criterion

Lifetime prediction

\begin{abstract}
A B S T R A C T
The radio-thermal oxidation of silane cross-linked polyethylene ( $\mathrm{Si}-\mathrm{XLPE}$ ) was studied in air under different $\gamma$ dose rates $\left(6.0,8.5,77.8\right.$, and $\left.400 \mathrm{~Gy} \cdot \mathrm{h}^{-1}\right)$ at different temperatures $\left(21,47\right.$, and $\left.86^{\circ} \mathrm{C}\right)$. The changes in the physico-chemical and mechanical properties of Si-XLPE throughout its exposure were determined by FTIR spectroscopy, differential scanning calorimetry (DSC), swelling measurements, rheometry in rubbery (DMTA) and in molten states, and uniaxial tensile testing. It was found that oxidation leads to the build-up of a wide variety of carbonyl and hydroxyl products (mostly carboxylic acids and hydroperoxides) and an efficient chain scission process that catastrophically reduces the concentration in elastically active chains and the elongation at break from the early periods of exposure. A new analytical model was derived from the current radio-thermal mechanistic scheme without making the usual assumption of thermal stability of hydroperoxides. After an initial period where the oxidation kinetics occurs with a constant rate, this model allows also predicting the auto-acceleration of the oxidation kinetics when the hydroperoxide concentration reaches a critical value of about $1.6 \times 10^{-1} \mathrm{~mol} \cdot \mathrm{L}^{-1}$. Choosing this critical value as a structural end-of-life criterion allows a more direct assessment of the lifetime of Si-XLPE in the various radio-thermal environments under study, except at the highest temperature (i.e. $86^{\circ} \mathrm{C}$ ) where the kinetic model can still be noticeably improved.
\end{abstract}

\section{Introduction}

Since the early 1980 s, in order to meet the urgent need of nuclear power plant operators, the polymer aging community is looking for a non-empirical approach for lifetime prediction of polymeric materials exposed in nuclear environments. A practical case that mobilized renowned research teams around the world is the radio-thermal ageing of electric cable insulations under normal operating conditions in a nuclear reactor. According to Khelidj et al. [1], at room temperature in air, the lifetime $t_{F}$ of electric cable insulations made of unfilled and unstabilised polyethylene (PE) varies with dose rate I according to the general trend depicted in Fig. 1. This almost universal long-term behavior of PE seems to be completely independent of its macromolecular structure (i.e. linear, branched or chemically cross-linked) and its crystallinity.

This curve displays a negative curvature in the domain of low dose rates where it tends towards a horizontal asymptote (when

\footnotetext{
* Corresponding author: Tel: + 331442461 47, Fax: +331 44246382. E-mail address: xavier.colin@ensam.eu (X. Colin).
}

$\mathrm{I} \rightarrow 0$ ) corresponding to the "ceiling lifetime" $t_{\mathrm{F} 0}$ due to "pure" thermal oxidation. Schematically, it can be decomposed into three distinct domains, each one corresponding to a different kinetic regime:

- "Pure" thermal oxidation predominates at very low dose rates (typically for $\mathrm{I}<\mathrm{I}_{\mathrm{T}} \approx 1.6 \times 10^{-7}$ Gy.s ${ }^{-1}$ ) and is characterised by very long lifetimes:

$\mathrm{t}_{F 0} \approx 18.5$ years

- "Pure" radio-oxidation predominates at high dose rates (typically for $\mathrm{I}>\mathrm{I}_{\mathrm{R}} \approx 5.0 \times 10^{-1}$ Gy. $\mathrm{s}^{-1}$ ) and is characterized by a lethal dose independent of the dose rate. As a result, the lifetime is proportional to the reciprocal dose rate:

$\mathrm{t}_{\mathrm{F}}=1.6 \times 10^{5} \mathrm{I}^{-1}$

- A combination of the two previous reactions occurs at intermediary dose rates (i.e. for $\mathrm{I}_{\mathrm{T}}<\mathrm{I}<\mathrm{I}_{\mathrm{R}}$ ), which is the range of practical interest for nuclear power plant operators. This radiothermal oxidation is initiated by two competitive sources of radicals, neither of which can be totally neglected compared to 


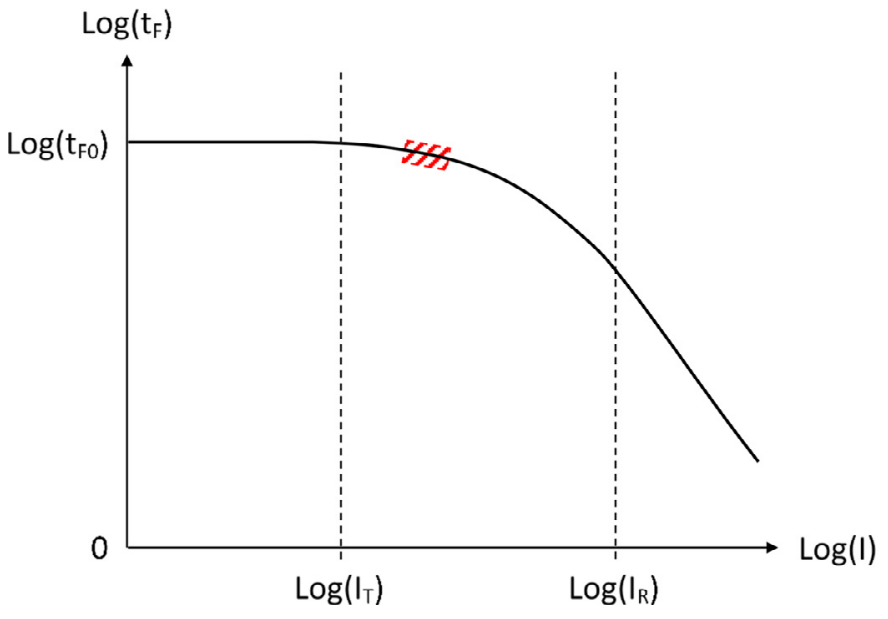

Fig. 1. Shape in logarithm co-ordinates of the lifetime $t_{F}$ versus $\gamma$ dose rate $I$ in air at room temperature for unstabilised and unfilled PE [1]. The shaded area (in red) corresponds to the normal operating conditions of electric cables in a nuclear reactor.

the other during the exposure [2]: polymer radiolysis (1R) and thermal decomposition of hydroperoxides (1T):

$$
\begin{aligned}
& \text { 1R) } \mathrm{PH}+\mathrm{h} v \rightarrow \mathrm{P}^{\bullet}+{ }^{1} / 2 \mathrm{H}_{2} \quad\left(\mathrm{r}_{\mathrm{i}}=10^{-7} \mathrm{G}_{\mathrm{i}} \mathrm{I}\right) \\
& \text { 1T) } \delta \mathrm{POOH} \rightarrow \lambda \mathrm{P}^{\bullet}+\mu \mathrm{PO}_{2}^{\bullet}\left(\mathrm{k}_{1}\right)
\end{aligned}
$$

where $r_{i}$ is the rate and $G_{i}$ is the radical yield (expressed in number of radicals $\mathrm{P}^{\bullet}$ per $100 \mathrm{eV}$ absorbed) of the radiochemical initiation. $\mathrm{k}_{1}$ is the rate constant and $\delta, \lambda$, and $\mu$ are stoichiometric coefficients describing the molecularity of thermal initiation such as:

$$
\begin{aligned}
& \mathrm{k}_{1}=\mathrm{k}_{1 \mathrm{u}}, \delta=1, \lambda=2 \text { and } \mu=0 \text { for unimolecular decomposi- } \\
& \text { tion, } \\
& \text { and } \mathrm{k}_{1}=\mathrm{k}_{1 \mathrm{~b}}, \delta=2 \text { and } \lambda=\mu=1 \text { for bimolecular decompo- } \\
& \text { sition. }
\end{aligned}
$$

To our knowledge, there is still no analytical equation for describing the entire shape of the curve $t_{F}=f(I)$ reported in Fig. 1.

In the second past half century, the vast majority of studies were devoted to the rigorous identification and understanding of the oxidation mechanisms, but exclusively at high dose rates where the duration and cost of aging experiments under irradiation can be significantly reduced [3-8]. When $I>I_{R}$, it was noted that the induction period is really too short to be measured. It was thus concluded that the oxidation kinetics already starts in steady regime from the early periods of exposure. In addition, it was also observed that the effect of dose rate is a simple kinetic consequence of the radio-oxidation reaction. Schematically, the formation rate of oxidation products is proportional to $\mathrm{I}^{1 / 2}$ when they result from the propagation step (of the mechanistic scheme), whereas it is proportional to I when they result from the initiation or termination step.

Based on only two assumptions: steady-state (for radical species) and thermal stability of hydroperoxides throughout the exposure, analytical equations were proposed in the literature to account for these experimental trends. As an example, the two following general equations were determined from a kinetic analysis of the mechanistic scheme for the formation rate $r_{Y}$ (expressed in mol. $\mathrm{L}^{-1}$ ) and the radiochemical yield $\mathrm{G}_{\mathrm{Y}}$ (dimensionless) of a given chemical event $Y$, respectively [1]:

$r_{Y}=10^{-7} G_{Y} I$

with $G_{Y}=10^{7} a_{Y}+10^{7} b_{Y} I^{-1 / 2}$ where $a_{Y}$ and $b_{Y} I^{-1 / 2}$ are initiation/termination and propagation terms, respectively.

However, even at low temperature close to ambient, the second assumption (thermal stability of hydroperoxides) can only be valid for sufficiently short durations. Indeed, it should be recalled that the rate of the thermal decomposition of hydroperoxides is an increasing function of their concentration [9]. Consequently, thermal initiation is expected to gradually gain in importance with the accumulation of hydroperoxides throughout the exposure, to finally become competitive with the radiochemical initiation. It is obvious that the global oxidation kinetics should be even more impacted in the case of an industrial application for which a very long lifetime of several decades is expected.

To our knowledge, the pioneering researchers in this field, to have propose a kinetic model in which irradiation generates hydroperoxides which decompose thermally to give radicals initiating new oxidation chains, are Gillen \& Clough [10]. Their model predicts an auto-acceleration of the oxidation kinetics during the exposure whereas, in all the previous models (for instance, see Eq. (3)), oxidation occurred at a constant rate. Unfortunately, Gillen \& Clough chosen questionable initial conditions: $[\mathrm{POOH}]=[\mathrm{POOH}]_{0}=0$ at $\mathrm{t}=0$. However, polymers (especially industrial grades having undergone processing operations) contain always thermally unstable species such as hydroperoxides, otherwise it would be difficult to explain their thermal or photochemical oxidizability. As a consequence of these unrealistic initial conditions, the model developed by Gillen \& Clough diverges in the domain of very low dose rates. Indeed, it predicts that $t_{F} \rightarrow \infty$ when $\mathrm{I} \rightarrow 0$.

In most recent publications [11,12], Gillen tried to get around this problem by relying on the research works of Ito [13-16] and Mares et al. [17]. He considered an extremely simplified radiothermal oxidation mechanistic scheme composed of only three first-order reactions: "pure" radio-oxidation, "pure" thermal oxidation, and their coupling, which is assumed to lead to synergistic effects. To take into account these synergistic effects, he defined a global time-dependent rate constant $\mathrm{k}_{\mathrm{R}+\mathrm{T}}$ as follows:

$\mathrm{k}_{\mathrm{R}+\mathrm{T}}(\mathrm{t})=\mathrm{k}_{\mathrm{R}}(\mathrm{t})+\mathrm{k}_{\mathrm{T}}(\mathrm{t})+\mathrm{k}_{\mathrm{S}}(\mathrm{t})$

where $k_{R}$ and $k_{T}$ are effective rate constants to be determined experimentally from the changes in mechanical properties (conventionally, elongation at break) in pure radiochemical (i.e. under high dose rate at low temperature) and pure thermal environments (i.e. in the absence of irradiation), respectively. The effective rate constant $\mathrm{k}_{\mathrm{S}}$ of the synergistic reaction is deduced from the changes in mechanical properties measured in radio-thermal environment.

Finally, Gillen defined the synergistic effects as follows:

$\mathrm{q}(\mathrm{t})=\frac{\mathrm{k}_{\mathrm{R}+\mathrm{T}}(\mathrm{t})}{\mathrm{k}_{\mathrm{R}}(\mathrm{t})+\mathrm{k}_{\mathrm{T}}(\mathrm{t})}=1+\frac{\mathrm{k}_{\mathrm{S}}(\mathrm{t})}{\mathrm{k}_{\mathrm{R}}(\mathrm{t})+\mathrm{k}_{\mathrm{T}}(\mathrm{t})}$

If the ratio $\mathrm{q}>1$, the synergistic effects are clearly indicated. However, as the rate constants $k_{R}, k_{T}$ and $k_{S}$ are time dependent, $\mathrm{q}$ varies non-monotonically throughout the exposure [11].

However, at its current state, this new approach is not yet completely convincing for the following reasons. From a practical point of view, it does not allow avoiding the issue of the choice of initial conditions. Instead of an initial concentration $\left([\mathrm{POOH}]_{0}\right)$, it is now necessary to determine an initial rate constant for thermal oxidation $\left(\mathrm{k}_{\mathrm{T} 0}\right)$, but also for radio-oxidation $\left(\mathrm{k}_{\mathrm{R} 0}\right)$ and for synergistic reaction $\left(\mathrm{k}_{\mathrm{SO}}\right)$.

From the perspective of a non-empirical lifetime prediction, this new approach raises a series of fundamental issues that have never been addressed by its author, for instance:

i) Eq. (5) was postulated but never justified. Thus, the assumption of a simple linear combination of the contributions of the 


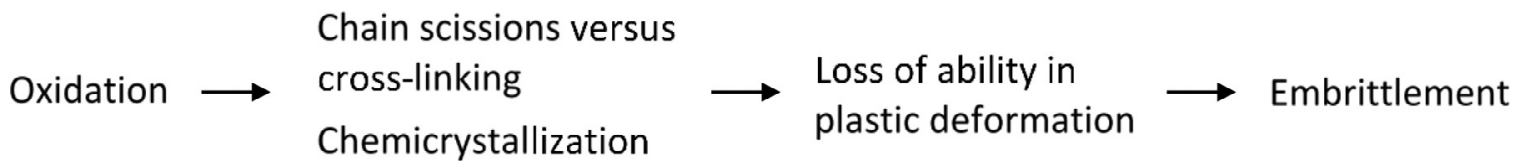

Fig. 2. Consequences of oxidation on the fracture properties of semi-crystalline polymers.

radio- and thermal oxidations and their synergistic effects remains to be demonstrated.

ii) Even if Eq. (5) was valid, it would remain to determine nonempirical equations for the three rate constants: $k_{R}, k_{T}$, and $\mathrm{k}_{\mathrm{S}}=\mathrm{f}(\mathrm{t})$.

iii) After having fully developed the kinetic model of radio-thermal oxidation, it will also remain to predict the consequences of chemical changes on the mechanical properties.

In our opinion, the two first issues could be solved by a careful kinetic analysis of the radio-thermal oxidation mechanistic scheme. In contrast, the last issue requires the rigorous identification and understanding of the embrittlement mechanisms and their kinetics (for instance, the relative predominance of chain scissions over cross-linking), but also the establishment of a series of structure/property relationships in order to fully describe the causal chain presented in Fig. 2, as already done, for instance, in references [18-21].

The present research work aims at developing a robust analytical model for accurately simulating the radio-thermal oxidation kinetics of electrical cable insulations in nuclear power plants. To reach this goal, a new analytical method for solving the system of differential equations derived from the mechanistic scheme will be detailed. Then, the reliability and limitations of the corresponding analytical solution will be checked experimentally from the changes in the physico-chemical properties of a silane crosslinked polyethylene (Si-XLPE) exposed in various radio-thermal environments. All these results will allow identifying accurately the radio-thermal oxidation behavior of this new generation insulating material, and will help to compare it with other types of PE much better known in the literature $[1,2]$, which will be naturally chosen as reference materials in this study.

\section{Experimental}

\subsection{Materials}

Free additive Si-XLPE films of about $500 \mu \mathrm{m}$ thick were directly provided by Nexans NRC. These films were produced by extrusion of a linear low density polyethylene (LDPE) grafted with vinyl trimethoxy silane side-groups. The chemical cross-linking was then performed by immersion in water at $65^{\circ} \mathrm{C}$ for $48 \mathrm{~h}$ [22]. The density and gel content of the resulting Si-XLPE are about 0.912 g.cm ${ }^{-3}$ and $71 \%$, respectively.

\subsection{Radio-thermal ageing conditions}

Radio-thermal ageing was performed in the Panoza facility at UJV Rez, Czech Republic, with a ${ }^{60}$ Co $\gamma$-ray source at different temperatures. All the exposure conditions are summarized in Table 1.
It should be noted that the ageing experiments numbered 1,3 , and 4 were performed at three distinct dose rates $(8.5,77.8$, and 400 Gy.h ${ }^{-1}$ ) at low temperature close to ambient in order to investigate the effect of dose rate on the oxidation kinetics. In contrast, ageing experiments numbered 1 and 2 were performed at almost the same dose rate $\left(6.0\right.$ and $\left.8.5 \mathrm{~Gy} \cdot \mathrm{h}^{-1}\right)$ but at two different temperatures $\left(47\right.$ and $86^{\circ} \mathrm{C}$ ) in order to investigate the effect of temperature on the oxidation kinetics.

\subsection{Experimental characterization}

\subsubsection{Uniaxial tensile testing}

After ageing, some films were characterized by uniaxial tensile testing to determine their lifetime $t_{F}$ and thus, compare the longterm durability of Si-XLPE with PE (see Fig. 1). The elongation at break $\varepsilon_{\mathrm{R}}$ was measured with a Instron $5500 \mathrm{~K} 8810 / 4505 \mathrm{H} 2190$ machine at $23^{\circ} \mathrm{C}, 50 \% \mathrm{RH}$ and a $50 \mathrm{~mm} \cdot \mathrm{min}^{-1}$ crosshead speed on dumb-bell specimens according to standards ISO 527-1:2012 and ISO 527-2:2012 [23,24]. For each radio-thermal ageing condition, $\varepsilon_{\mathrm{R}}$ was plotted as a function of the time of exposure and the corresponding lifetime $t_{\mathrm{F}}$ was determined using the conventional endof-life criterion $\varepsilon_{\mathrm{F}}$ for electric cable application in nuclear industry: $\mathrm{t}=\mathrm{t}_{\mathrm{F}}$ when $\varepsilon_{\mathrm{R}}=\varepsilon_{\mathrm{F}}=50 \%$.

\subsubsection{FTIR spectroscopy}

Other films were characterized by classical physico-chemical laboratory techniques to evaluate the progress of oxidation and to determine the consequences of oxidation on the structure of the macromolecular network. In particular, FTIR spectroscopy was used in transmission mode to monitor and titrate the oxidation products. FTIR spectra were recorded from 4000 to $400 \mathrm{~cm}^{-1}$ with a Perkin Elmer FTIR Frontier spectrometer, after averaging the 16 scans obtained with a resolution of $4 \mathrm{~cm}^{-1}$. For each film, at least three FTIR measurements were performed. As expected, a large amount of carbonyl and hydroxyl products was detected within the film samples from the early periods of exposure.

As an example, Fig. 3 shows the changes in the carbonyl region (i.e. between 1650 and $1800 \mathrm{~cm}^{-1}$ ) of the IR spectrum in air under the highest (i.e. $400 \mathrm{~Gy} \cdot \mathrm{h}^{-1}$ ) and lowest dose rates (8.5 Gy.h ${ }^{-1}$ ) at low temperature close to ambient. In both cases, it can be clearly observed that a broad IR absorption band centered at 1714 $\mathrm{cm}^{-1}$ rapidly builds up. According to literature [25-30], this band is mainly attributed to the stretching vibration of the $\mathrm{C}=\mathrm{O}$ bond of carboxylic acids. However, due to its large width, the presence of many other secondary carbonyl products such as: unsaturated (at 1690-1705 $\mathrm{cm}^{-1}$ ) and saturated ketones (1720-1725 $\mathrm{cm}^{-1}$ ), aldehydes (1730-1735 $\left.\mathrm{cm}^{-1}\right)$, linear (1740-1750 $\left.\mathrm{cm}^{-1}\right)$ and cyclic esters (i.e. $\gamma$-lactones, $1780-1790 \mathrm{~cm}^{-1}$ ), is highly probable [25-30].

In the same way, it was clearly observed that an even broader IR absorption band in the hydroxyl region (i.e. between 3100 and

Table 1

Radio-thermal ageing conditions.

\begin{tabular}{llllll}
\hline Ageing no. & Dose rate $\left(\mathbf{G y . h} \mathbf{h}^{\mathbf{- 1}}\right)$ & Dose rate $\left(\mathbf{G y . s}^{-\mathbf{1}}\right)$ & Temperature $\left({ }^{\circ} \mathbf{C}\right)$ & Maximum duration $(\mathbf{h})$ & Maximum dose $(\mathbf{k G y )}$ \\
\hline $\mathbf{1}$ & 8.5 & $2.36 \times 10^{-3}$ & 47 & 12800 & 109 \\
$\mathbf{2}$ & 6.0 & $1.67 \times 10^{-3}$ & 86 & 16267 & 98 \\
$\mathbf{3}$ & 77.8 & $2.16 \times 10^{-2}$ & 47 & 3830 & 298 \\
$\mathbf{4}$ & 400 & $1.11 \times 10^{-1}$ & 21 & 668 & 269 \\
\hline
\end{tabular}



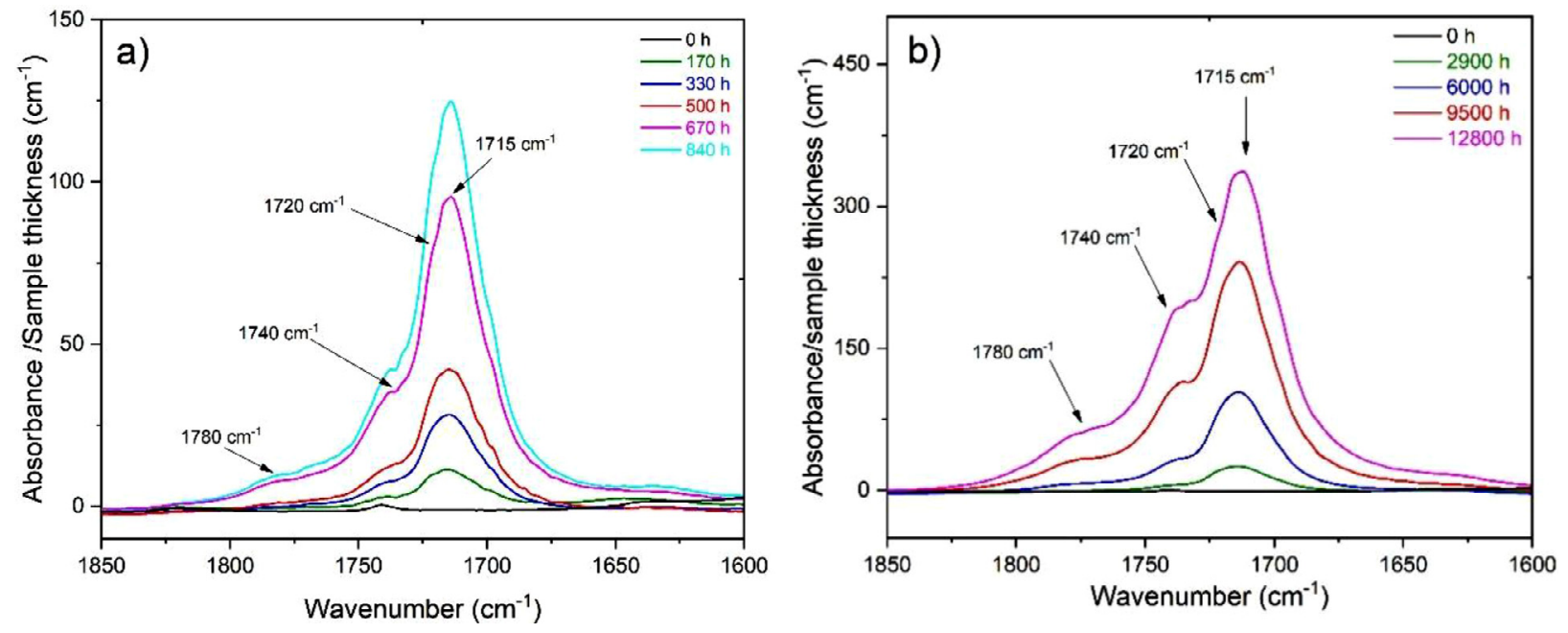

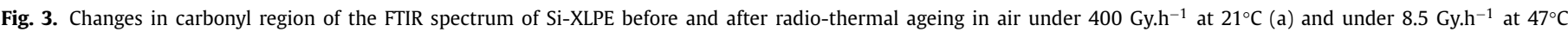
(b).
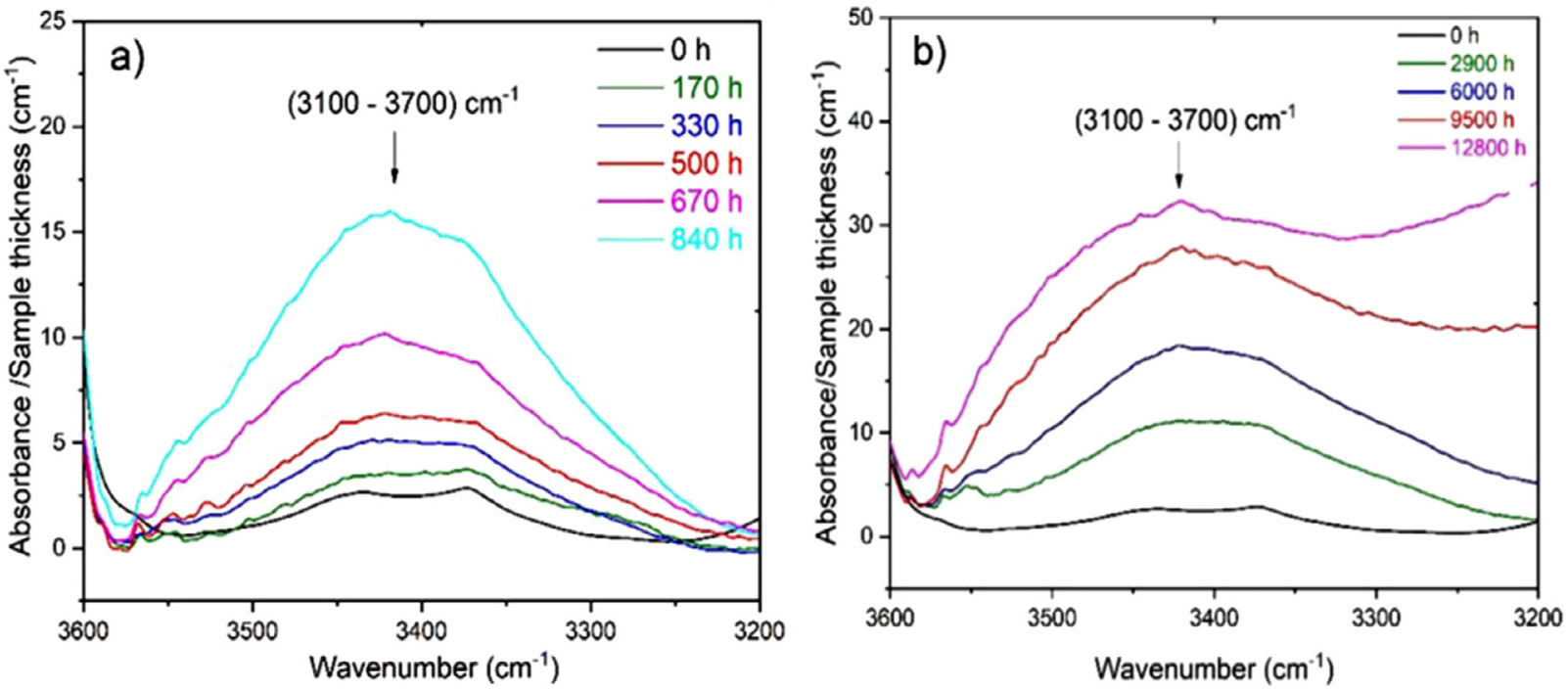

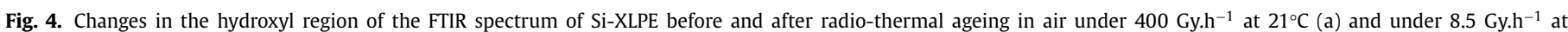
$47^{\circ} \mathrm{C}$ (b).

$3700 \mathrm{~cm}^{-1}$, see Fig. 4) also quickly grows. According to literature [25,27-30], this band is attributed to the stretching vibration of the $\mathrm{O}-\mathrm{H}$ bond of hydroperoxides, alcohols, and carboxylic acids.

The concentrations of carboxylic acids and hydroxyl products [Prod] were determined by applying the classical Beer-Lambert's law:

[Prod $]=\frac{\mathrm{OD}}{\mathrm{ep} \varepsilon}$

where OD is the optical density of the IR absorption band (dimensionless), $\varepsilon$ is the molar extinction coefficient for the corresponding oxidation product (expressed in $\mathrm{L} \cdot \mathrm{mol}^{-1} \cdot \mathrm{cm}^{-1}$ ), and ep is the film thickness (in $\mathrm{cm}$ ).

The orders of magnitude of $\varepsilon$ were determined in a previous publication [28]. It was found that $\varepsilon=680$ and $70 \mathrm{~L} . \mathrm{mol}^{-1} . \mathrm{cm}^{-1}$ for carboxylic acids and hydroxyls, respectively.

\subsubsection{Differential scanning calorimetry}

Differential scanning calorimetry (DSC) was used under pure nitrogen to monitor and titrate the hydroperoxides ( $\mathrm{POOH})$, but also to highlight the changes in crystalline morphology during the exposure. DSC thermograms were recorded with a TA instruments
DSC Q1000 calorimeter beforehand calibrated with an indium reference. Film samples with a mass ranged between 5 and $10 \mathrm{mg}$ were introduced in a closed standard aluminum pan to be analyzed between $-50^{\circ} \mathrm{C}$ and $250^{\circ} \mathrm{C}$, with a heating rate of $10^{\circ} \mathrm{C} . \mathrm{min}^{-1}$ under a nitrogen flow of $50 \mathrm{~mL} \cdot \mathrm{min}^{-1}$.

As an example, Fig. 5 shows the changes in the DSC thermogram in air under the highest (i.e. $400 \mathrm{~Gy} \cdot \mathrm{h}^{-1}$ ) and lowest dose rates $\left(8.5 \mathrm{~Gy} \cdot \mathrm{h}^{-1}\right)$ at low temperature close to ambient. It can be clearly observed that an exothermic peak starts to grow above the melting zone of the crystalline phase. This new peak is typically ranged between 130 and $230^{\circ} \mathrm{C}$. As shown in a previous publication [28], it results from the thermal decomposition of $\mathrm{POOH}$ in the DSC cavity.

The concentration of hydroperoxides [POOH] was determined as follows:

$[\mathrm{POOH}]=\frac{\Delta \mathrm{H}_{\mathrm{POOH}}}{\Delta \mathrm{H}_{\text {theory }}}$

where $\Delta \mathrm{H}_{\mathrm{POOH}}$ is the area under the exothermic peak between 130 and $230^{\circ} \mathrm{C}$ on the DSC thermogram and $\Delta \mathrm{H}_{\text {theory }}$ is the theoretical value of the decomposition enthalpy of $\mathrm{POOH}$, which can be 

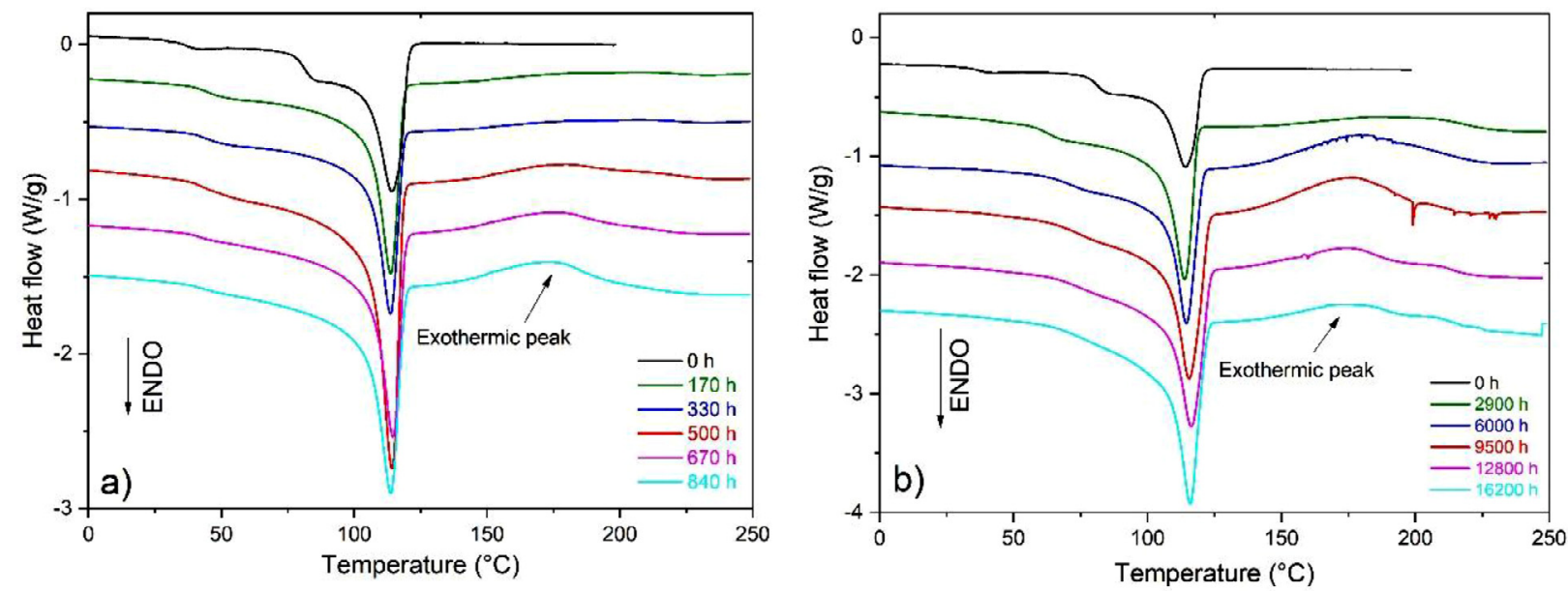

Fig. 5. Changes in the DSC thermogram of Si-XLPE before and after radio-thermal ageing in air under $400 \mathrm{~Gy} \cdot \mathrm{h}^{-1}$ at $21^{\circ} \mathrm{C}(\mathrm{a})$ and under $^{\circ} \cdot 5 \mathrm{~Gy} \cdot \mathrm{h}^{-1}$ at $47^{\circ} \mathrm{C}(\mathrm{b})$.

calculated from the classical theoretical concepts of thermochemistry or determined experimentally from $\mathrm{POOH}$ model compounds: $\Delta \mathrm{H}_{\text {theory }}=291 \mathrm{~kJ} \cdot \mathrm{mol}^{-1}[28]$.

In addition, the global crystallinity ratio $\mathrm{X}_{C}$ of the polymer was determined with the common equation:

$\mathrm{X}_{\mathrm{C}}=\frac{\Delta \mathrm{H}_{\mathrm{m}}}{\Delta \mathrm{H}_{\mathrm{m} 0}} \times 100$

where $\Delta \mathrm{H}_{\mathrm{m}}$ is the sum of the areas under the endothermic peaks observed between 50 and $125^{\circ} \mathrm{C}$ on the DSC thermogram, and $\Delta \mathrm{H}_{\mathrm{m} 0}$ is the melting enthalpy of the PE crystal: $\Delta \mathrm{H}_{\mathrm{m} 0}=292 \mathrm{~J} \cdot \mathrm{g}^{-1}$ [31].

\subsubsection{Swelling measurements}

Film samples were swelled with a good solvent to determine their swelling ratio and deduce the concentration of elastically active chains in the macromolecular network. A sample having an initial mass $\mathrm{m}_{\mathrm{i}}$ was introduced into xylene previously heated at $130^{\circ} \mathrm{C}$ for 24 hours until reaching its equilibrium mass $m_{S}$ after complete swelling. This sample was then dried under vacuum at $80^{\circ} \mathrm{C}$ for 48 hours in order to determine the gel mass $m_{d}$. The swelling ratio $\mathrm{Q}$ was calculated as follows:

$\mathrm{Q}=1+\frac{\rho_{\mathrm{pol}}}{\rho_{\mathrm{sol}}} \cdot \frac{\left(\mathrm{m}_{\mathrm{S}}-\mathrm{m}_{\mathrm{d}}\right)}{\mathrm{m}_{\mathrm{d}}}$

where $\rho_{\text {pol }}$ and $\rho_{\text {sol }}$ are the respective densities of $\operatorname{Si}-\operatorname{XLPE}\left(\rho_{\text {pol }}=\right.$ $0.912)$ and xylene $\left(\rho_{\text {sol }}=0.761\right)$.

The Flory-Rhener's theory [32] was then used to determine the concentration of elastically active chains $v$ between two consecutive chemical cross-links in the macromolecular network:

$v=\frac{\left[\ln \left(1-\mathrm{V}_{\mathrm{r} 0}\right)+\mathrm{V}_{\mathrm{r} 0}+\chi \mathrm{V}_{\mathrm{r} 0}^{2}\right]}{\mathrm{V}_{\mathrm{sol}}\left[\mathrm{V}_{\mathrm{r} 0}^{\frac{1}{3}}-\frac{2 \mathrm{~V}_{\mathrm{r} 0}}{\mathrm{f}}\right]}$

where $V_{\text {sol }}$ is the molar volume of xylene $\left(V_{\text {sol }}=139.3 \mathrm{~cm}^{3} \cdot \mathrm{mol}^{-1}\right)$, $\chi$ is the Flory-Huggins' interaction parameter between xylene and $\operatorname{Si}-X \operatorname{LPE}(\chi=0.31[33,34]), \mathrm{f}$ is the functionality of chemical crosslinks ( $\mathrm{f}=4$ for Si-XLPE) and $\mathrm{V}_{\mathrm{r} 0}$ is the volumic fraction of polymer in the swollen macromolecular network, of which expression is given below:

$\mathrm{V}_{\mathrm{r} 0}=\frac{1}{1+\frac{(\mathrm{Q}-1) \rho_{\mathrm{pol}}}{\rho_{\mathrm{sol}}}}$

\subsubsection{Rheometry in solid state (DMTA)}

Rheometry in solid state (DMTA) was used in tension mode to determine the storage modulus E' at the rubbery plateau and

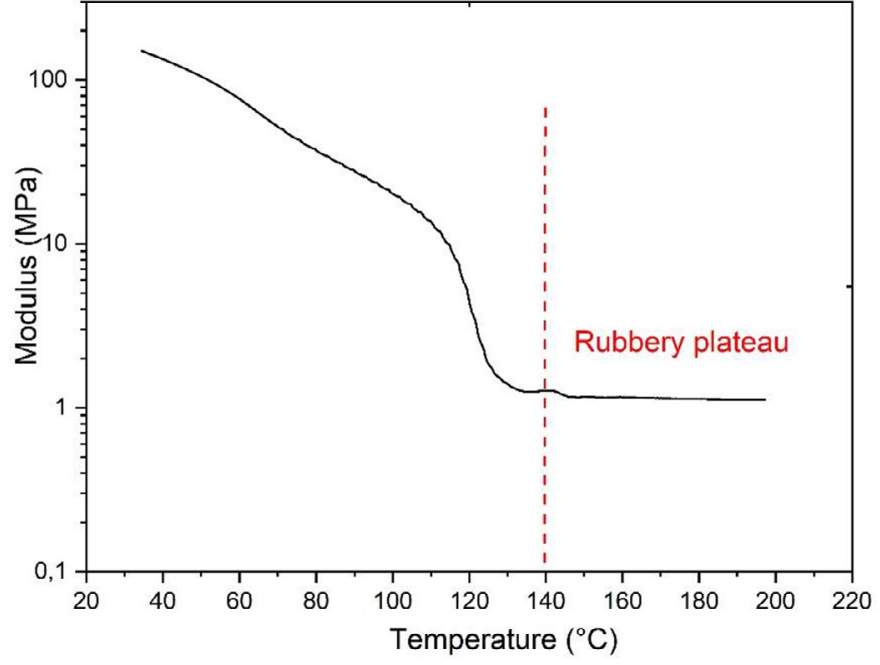

Fig. 6. DMTA thermogram of unaged Si-XLPE.

check the concentrations of elastically active chains determined by swelling in xylene. DMTA thermograms were recorded with a TA instruments DMA Q800 viscoelastic analyzer. Parallelepipedic film samples of about $30.3 \mathrm{~mm}$ long and $6.3 \mathrm{~mm}$ large were attached to the device clamps to be analyzed between 25 and $200^{\circ} \mathrm{C}$, with a heating rate of $3^{\circ} \mathrm{C} \cdot \mathrm{min}^{-1}$, a frequency of $1 \mathrm{~Hz}$, and a strain amplitude of $0.2 \%$ under nitrogen.

As an example, Fig. 6 shows the DMTA thermogram of Si-XLPE before its radio-thermal ageing. It can be clearly observed that the melting of the crystalline phase leads to sudden decrease of the storage modulus of more than one decade around $120^{\circ} \mathrm{C}$. The rubbery plateau of the completely amorphous Si-XLPE is clearly visible for temperatures higher than $140^{\circ} \mathrm{C}$.

The Flory's theory [35] was used to determine the total concentration of elastically active chains $v_{\mathrm{t}}$ from the values of E' measured at $140^{\circ} \mathrm{C}$ :

$\mathrm{E}^{\prime}=3 v_{\mathrm{t}} \rho_{\mathrm{pol}} \mathrm{RT}$

where $\rho_{\text {pol }}$ is the polymer density at $140^{\circ} \mathrm{C}\left(\rho_{\text {pol }}=897 \mathrm{~kg} \cdot \mathrm{m}^{-3}\right), \mathrm{R}$ is the perfect gas constant $\left(\mathrm{R}=8.314 \mathrm{~Pa} \cdot \mathrm{m}^{3} \cdot \mathrm{mol}^{-1} \cdot \mathrm{K}^{-1}\right)$, and $\mathrm{T}$ is the absolute temperature (expressed in $\mathrm{K}$ ).

When the macromolecular network is not swollen by a solvent, in addition to chemical cross-links, it is expected that E' depends also on a second type of cross-links, which are not of a chemical 
but physical nature, namely entanglements. In a first approach, $v_{\mathrm{t}}$ can be written as the sum of these two contributions:

$v_{\mathrm{t}}=v+v_{\mathrm{e}}$

where $v_{\mathrm{e}}$ would be the concentration of elastically active chains resulting only from entanglements in the macromolecular network (i.e. in the total absence of chemical cross-links). The value of $v_{\mathrm{e}}$ can be simply deduced by comparing the rheometry and swelling data.

For the unaged Si-XLPE, it was found that: $v_{\mathrm{t}}=0.14 \pm$ $0.01 \mathrm{~mol} . \mathrm{L}^{-1}$ and $v=0.12 \pm 0.02 \mathrm{~mol} . \mathrm{L}^{-1}$, so that: $v_{\mathrm{e}}=0.03 \pm$ $0.02 \mathrm{~mol} . \mathrm{L}^{-1}$. In other words, it was found that $v_{\mathrm{e}}$ is very low and almost of the same order of magnitude than the experimental scattering of $v$, i.e. almost undetectable. It was thus concluded that there are too few entanglements to significantly influence the concentration of elastically active chains. Consequently, entanglements were neglected in Si-XLPE and the concentration of elastically active chains $v$ resulting only from chemical cross-links was simply deduced as follows:

$v=\frac{\mathrm{E}^{\prime}}{3 \rho_{\mathrm{pol}} \mathrm{RT}}$

\subsubsection{Rheometry in molten state}

For the radio-thermal ageing conditions under consideration, chain scissions were found very efficient in Si-XLPE. Indeed, a very advanced damage of the macromolecular network was observed for moderate to high conversion ratios of the oxidation reaction, as the film samples were almost completely dissolved in xylene and their rubbery plateau was no longer detected by DMTA (the polymer passed directly from semi-crystalline to molten state). Therefore, when swelling and DMTA measurements were no longer possible, rheometry in molten state was performed at $140^{\circ} \mathrm{C}$ to determine the shear modulus $G^{\prime}$ and thus, access the concentration of elastically active chains. Strain sweep curves were recorded with a TA Instruments ARES viscoelastic analyzer. Disc film samples of 25 $\mathrm{mm}$ diameter and $1 \mathrm{~mm}$ thick were introduced in a coaxial parallel plate geometry to be analyzed at $140^{\circ} \mathrm{C}$ with an angular frequency of 1 rad.s ${ }^{-1}$ and a strain amplitude ranging between 0.01 and $100 \%$ under nitrogen flow.

As an example, Fig. 7 shows the strain sweep curve after $167 \mathrm{~h}$ of radio-thermal exposure in air under the highest dose rate (i.e. $400 \mathrm{~Gy} \cdot \mathrm{h}^{-1}$ ) at room temperature. As expected, it can be observed that $G^{\prime}$ reaches a constant value in the domain of low strains (typically for $\varepsilon<10 \%$ ) where linear viscoelasticity is valid. This value

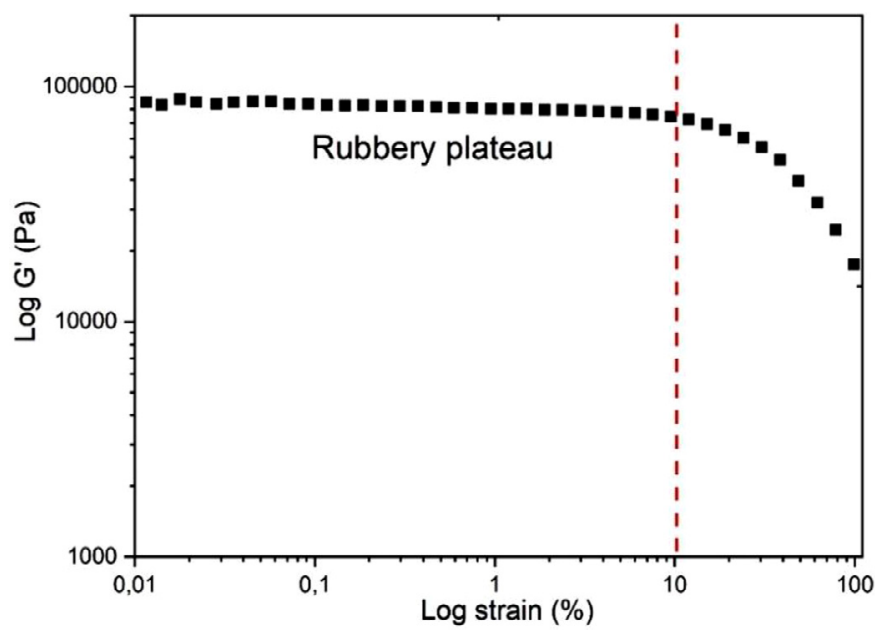

Fig. 7. Sweep strain curve of Si-XLPE after $167 \mathrm{~h}$ of exposure in air under 400 Gy.h $\mathrm{h}^{-1}$ at $21^{\circ} \mathrm{C}$. was thus chosen for calculating the concentration of elastically active chains with Eq. (15). Knowing that: $E^{\prime}=3 G^{\prime}$, it comes finally:

$v=\frac{\mathrm{G}^{\prime}}{\rho_{\mathrm{pol}} \mathrm{RT}}$

\section{Theory}

\subsection{Radio-thermal oxidation mechanistic scheme}

As said in introduction, in the domain of practical interest for nuclear power plant operators (i.e. for $1.6 \times 10^{-7}<\mathrm{I}<5.0 \times 10^{-1}$ Gy. $s^{-1}$ ), oxidation is initiated by both polymer radiolysis (1R) and thermal decomposition of hydroperoxides (1T). The corresponding radio-thermal oxidation mechanistic scheme can be thus written as follows:

Initiation:

1R) $\mathrm{PH}+\mathrm{hn} \rightarrow \mathrm{P}^{\bullet}+{ }^{1} / 2 \mathrm{H}_{2} \quad\left(\mathrm{r}_{\mathrm{i}}=10^{-7} \mathrm{G}_{\mathrm{i}} \mathrm{I}\right)$

1T) $\delta \mathrm{POOH} \rightarrow \lambda \mathrm{P}^{\bullet}+\mu \mathrm{PO}_{2}^{\bullet} \quad\left(\mathrm{k}_{1}\right)$

Propagation:

2) $\mathrm{P}^{\bullet}+\mathrm{O}_{2} \rightarrow \mathrm{PO}_{2}^{\bullet}\left(\mathrm{k}_{2}\right)$

3) $\mathrm{PO}_{2}^{\bullet}+\mathrm{PH} \rightarrow \mathrm{POOH}+\mathrm{P}^{\bullet}\left(\mathrm{k}_{3}\right)$

Terminations:

4) $\mathrm{P}^{\bullet}+\mathrm{P}^{\bullet} \rightarrow$ Inactive products $\left(\mathrm{k}_{4}\right)$

5) $\mathrm{P}^{\bullet}+\mathrm{PO}_{2}^{\bullet} \rightarrow$ Inactive products $\left(\mathrm{k}_{5}\right)$

6) $\mathrm{PO}_{2}{ }^{\bullet}+\mathrm{PO}_{2}{ }^{\bullet} \rightarrow$ Inactive products $+\mathrm{O}_{2}\left(\mathrm{k}_{6}\right)$

where $\mathrm{PH}, \mathrm{POOH}, \mathrm{P}^{\bullet}$, and $\mathrm{PO}_{2}^{\bullet}$ designate an oxidation site, an hydroperoxide, alkyl and peroxy radicals, respectively. $\delta, \lambda$, and $\mu$ are stoichiometric coefficients. $r_{i}, G_{i}$, and $k_{j}$ (with $j=1, \ldots, 6$ ) are a rate, the radical yield, and rate constants, respectively.

In most cases of "pure" thermal oxidation, $\mathrm{POOH}$ decomposition is exclusively unimolecular at high temperature (i.e. $\mathrm{k}_{1}=\mathrm{k}_{1 \mathrm{u}}$, $\delta=1, \lambda=2$, and $\mu=0$ ) or mainly bimolecular at moderate to low temperature $\left(\mathrm{k}_{1}=\mathrm{k}_{1 \mathrm{~b}}, \delta=2\right.$, and $\left.\lambda=\mu=1\right)$, but rarely a combination of both modes. In fact, it can easily be shown that there is a hyperbolic shape boundary delimiting the two domains in which each thermal initiation predominates over each other in a map $(\mathrm{T}, \mathrm{t})$. This boundary corresponds to a critical hydroperoxide concentration $[\mathrm{POOH}]_{\mathrm{C}}$ reached when the respective rates of the two thermal initiation modes are equal [3]. Since the activation energy is higher for the unimolecular than bimolecular mode: $\mathrm{E}_{1 \mathrm{u}}>\mathrm{E}_{1 \mathrm{~b}},[\mathrm{POOH}]_{\mathrm{C}}$ is an increasing function of temperature. In PE, it writes [36]:

$[\mathrm{POOH}]_{\mathrm{C}}=\frac{\mathrm{k}_{1 \mathrm{u}}}{\mathrm{k}_{1 \mathrm{~b}}}=2.9 \times 10^{3} \operatorname{Exp}\left(-\frac{35000}{\mathrm{RT}}\right)$

The numerical application of Eq. (17) gives that $[\mathrm{POOH}]_{\mathrm{C}}$ would be ranged between $10^{-3}$ and $10^{-2}$ mol. $\mathrm{L}^{-1}$ at low temperature close to ambient for PE. This is the same order of magnitude of the initial concentration of hydroperoxides $[\mathrm{POOH}]_{0}$ usually reported in the literature for many hydrocarbon polymers [28,37]. That is the reason why, in the present study, it will be considered that "pure" thermal oxidation is directly initiated in bimolecular mode:

1b) $2 \mathrm{POOH} \rightarrow \mathrm{P}^{\bullet}+\mathrm{PO}_{2}^{\bullet}\left(\mathrm{k}_{1 \mathrm{~b}}\right)$ 


\subsection{System of differential equations}

At the low conversion ratios of the oxidation reaction (i.e. for $[\mathrm{PH}] \approx[\mathrm{PH}]_{0} \approx$ constant), the following system of differential equations can be derived from the previous radio-thermal oxidation mechanistic scheme:

$$
\begin{aligned}
\frac{\mathrm{d}\left[\mathrm{P}^{\bullet}\right]}{\mathrm{dt}}= & \mathrm{r}_{\mathrm{i}}+\mathrm{k}_{1 \mathrm{~b}}[\mathrm{POOH}]^{2}-\mathrm{k}_{2} \mathrm{C}\left[\mathrm{P}^{\bullet}\right]+\mathrm{k}_{3}\left[\mathrm{PO}_{2}^{\bullet}\right][\mathrm{PH}]-2 \mathrm{k}_{4}\left[\mathrm{P}^{\bullet}\right]^{2} \\
& -\mathrm{k}_{5}\left[\mathrm{P}^{\bullet}\right]\left[\mathrm{PO}_{2}^{\bullet}\right]
\end{aligned}
$$

$$
\begin{aligned}
\frac{\mathrm{d}\left[\mathrm{PO}_{2}^{\bullet}\right]}{\mathrm{dt}}= & \mathrm{k}_{1 \mathrm{~b}}[\mathrm{POOH}]^{2}+\mathrm{k}_{2} \mathrm{C}\left[\mathrm{P}^{\bullet}\right]-\mathrm{k}_{3}\left[\mathrm{PO}_{2}^{\bullet}\right][\mathrm{PH}]-\mathrm{k}_{5}\left[\mathrm{P}^{\bullet}\right]\left[\mathrm{PO}_{2}^{\bullet}\right] \\
& -2 \mathrm{k}_{6}\left[\mathrm{PO}_{2}^{\bullet}\right]^{2}
\end{aligned}
$$

$$
\frac{\mathrm{d}[\mathrm{POOH}]}{\mathrm{dt}}=-2 \mathrm{k}_{1 \mathrm{~b}}[\mathrm{POOH}]^{2}+\mathrm{k}_{3}\left[\mathrm{PO}_{2}^{\bullet}\right][\mathrm{PH}]
$$

where the oxygen concentration $C$ is related to the oxygen partial pressure $\mathrm{P}_{\mathrm{O} 2}$ in the exposure environment by the classical Henry's law:

$\mathrm{C}=\mathrm{S} \cdot \mathrm{P}_{\mathrm{O} 2}$

and $S$ is the coefficient of oxygen solubility into the polymer. Typical values of $S$ reported for low density polyethylene (LDPE) in the literature are about $1.8 \times 10^{-8} \mathrm{~mol} . \mathrm{L}^{-1} \cdot \mathrm{Pa}^{-1}$ regardless the temperature [38]. Knowing that in air under atmopspheric pressure: $\mathrm{P}_{\mathrm{O} 2}=0.21 \times 10^{5} \mathrm{~Pa}$, it comes finally: $\mathrm{C}=3.8 \times 10^{-4} \mathrm{~mol} . \mathrm{L}^{-1}$.

There is no rigorous analytical solution for this system of differential equations, which can be solved numerically without any simplifying assumption [2]. However, an approached analytical solution would be very useful because it would allow appreciating the behavioral trends of the reactive species $\left[\mathrm{P}^{\circ}\right],\left[\mathrm{PO}_{2}{ }^{\circ}\right],[\mathrm{POOH}]$ with key exposure parameters, in particular: $\gamma$ dose rate I, temperature $\mathrm{T}$, and oxygen partial pressure $\mathrm{P}_{\mathrm{O} 2}$. In addition, this analytical solution would then allow calculating key physico-chemical properties, from a practical point of view, because they can be checked experimentally, such as: oxygen consumption $(\mathrm{Q})$, carbonyl buildup $([\mathrm{P}=\mathrm{O}])$, damage state of macromolecular network $(v)$, etc. (see section 3.4). Finally, if a structural end-of-life criterion was identified, it would be then possible to propose an equation for predicting the lifetime of the insulating material (see section 3.5).

Analytical solving is only possible through the use of simplifying assumptions. As said in introduction, the two most widely used simplifying assumptions are: steady-state (for radical species) and thermal stability of hydroperoxides. If the first assumption seems to be well founded and allows explaining the constancy of the oxidation rate in the first periods of exposure in radio-thermal environments, in contrast, the second one prevents accounting for the auto-acceleration of the oxidation kinetics in the rest of the exposure. This acceleration is due to the decomposition of hydroperoxides above a critical concentration $[\mathrm{POOH}]_{\mathrm{F}}$, which is assumed to be a fraction of the steady concentration of hydroperoxides $[\mathrm{POOH}]_{\infty}$ reached in the case of "pure" thermal oxidation [2].

Next sections are devoted to the proposal and validation of a sound analytical kinetic model for radio-thermal oxidation taking into account the hydroperoxide decomposition.

\subsection{Analytical solving}

Denote $r_{1}$ the global initiation rate of the oxidation reaction. It writes as the sum of the radiochemical and thermal initiation rates:

$\mathrm{r}_{1}=\mathrm{r}_{\mathrm{i}}+2 \mathrm{k}_{1}[\mathrm{POOH}]^{2}$

In all the developments which follow, it will be assumed that oxidation is mainly initiated by the polymer radiolysis throughout the exposure (i.e. $r_{i} \gg 2 k_{1}[\mathrm{POOH}]^{2}$ ) even if, at long-term, hydroperoxide decomposition is added as additional (but secondary) source of radicals. In other words, only the right part of the domain of intermediary dose rates will be the subject of a kinetic analysis (see Fig. 1).

Applying the steady-state assumption to radical species leads to:

$\frac{\mathrm{d}[\mathrm{P} \bullet}{\mathrm{dt}}+\frac{\mathrm{d}\left[\mathrm{PO}_{2}^{\bullet}\right]}{\mathrm{dt}}=0$

i.e. $\mathrm{k}_{4}\left[\mathrm{P}^{\bullet}\right]^{2}+\mathrm{k}_{5}\left[\mathrm{P}^{\bullet}\right]\left[\mathrm{PO}_{2}^{\bullet}\right]+\mathrm{k}_{6}\left[\mathrm{PO}_{2}^{\bullet}\right]^{2}-\frac{\mathrm{r}_{1}}{2}=0$

whose positive root is:

$\left[\mathrm{P}^{\bullet}\right]=\frac{\mathrm{k}_{5}\left[\mathrm{PO}_{2}^{\bullet}\right]}{2 \mathrm{k}_{4}}\left\{-1+\left[1+\psi\left(\frac{\left[\mathrm{PO}_{2}^{\bullet}\right]_{0}^{2}}{\left[\mathrm{PO}_{2}^{\bullet}\right]^{2}}-1\right)\right]^{1 / 2}\right\}$

where $\Psi$ is a kinetic parameter quantifying the competition between the different terminations of radical species:

$\psi=\frac{4 \mathrm{k}_{4} \mathrm{k}_{6}}{\mathrm{k}_{5}^{2}}$

and $\left[\mathrm{PO}_{2}^{\bullet}\right]_{0}$ is the steady concentration of peroxy radicals in oxygen excess:

$\left[\mathrm{PO}_{2}^{*}\right]_{0}=\left(\frac{\mathrm{r}_{1}}{2 \mathrm{k}_{6}}\right)^{1 / 2}$

i.e. $\left[\mathrm{PO}_{2}^{*}\right]_{0}=\left(\frac{\mathrm{r}_{\mathrm{i}}}{2 \mathrm{k}_{6}}\right)^{1 / 2}\left(1+\frac{2 \mathrm{k}_{1}[\mathrm{POOH}]^{2}}{\mathrm{r}_{\mathrm{i}}}\right)^{1 / 2}(28)$

i.e. $\left[\mathrm{PO}_{2}^{\bullet}\right]_{0} \approx\left(\frac{\mathrm{r}_{\mathrm{i}}}{2 \mathrm{k}_{6}}\right)^{1 / 2}$

As expected, $\left[\mathrm{PO}_{2}^{\circ}\right]_{0}$ takes approximatively the same value as in a "pure" radiochemical environment [39].

If, as shown by Gillen et al. [40], $\Psi<<1$, then there is a more or less wide range of oxygen concentrations for which:

$1 \geq \frac{\left[\mathrm{PO}_{2}^{\bullet}\right]^{2}}{\left[\mathrm{PO}_{2}^{*}\right]_{0}^{2}}>\frac{5 \psi}{1+5 \psi}$

In this range of oxygen concentrations, Eq. (25) can be simplified as follows:

$\left[\mathrm{P}^{\bullet}\right]=\frac{2 \mathrm{k}_{6}}{\mathrm{k}_{5}}\left(\left[\mathrm{PO}_{2}^{\bullet}\right]_{0}-\left[\mathrm{PO}_{2}^{\bullet}\right]\right)$

If introducing Eq. (31) into Eq. (19) and if applying the steadystate assumption to peroxy radicals, it comes finally:

$\left[\mathrm{PO}_{2}^{\bullet}\right]=\left[\mathrm{PO}_{2}^{\bullet}\right]_{0} \frac{\beta \mathrm{C}}{1+\beta \mathrm{C}}$

i.e. $\left[\mathrm{PO}_{2}^{\bullet}\right]=\left(\frac{\mathrm{r}_{\mathrm{i}}}{2 \mathrm{k}_{6}}\right)^{1 / 2} \frac{\beta \mathrm{C}}{1+\beta \mathrm{C}}$

where $\beta^{-1}$ corresponds to the critical value of the oxygen concentration $C_{C}$ above which oxygen excess is reached:

$\beta=\frac{1}{\mathrm{C}_{\mathrm{C}}}=\frac{2 \mathrm{k}_{6} \mathrm{k}_{2}}{\mathrm{k}_{5}\left[\mathrm{k}_{3}[\mathrm{PH}]+\left(2 \mathrm{r}_{1} \mathrm{k}_{6}\right)^{1 / 2}\right]}$

i.e. $\beta=\frac{2 \mathrm{k}_{6} \mathrm{k}_{2}}{\mathrm{k}_{5}\left[\mathrm{k}_{3}[\mathrm{PH}]+\left(2 \mathrm{r}_{\mathrm{i}} \mathrm{k}_{6}\right)^{1 / 2}\left(1+\frac{2 \mathrm{k}_{1}[\mathrm{POOH}]^{2}}{\mathrm{r}_{\mathrm{i}}}\right)^{1 / 2}\right]}$

i.e. $\beta \approx \frac{2 \mathrm{k}_{6} \mathrm{k}_{2}}{\mathrm{k}_{5}\left[\mathrm{k}_{3}[\mathrm{PH}]+\left(2 \mathrm{r}_{\mathrm{i}} \mathrm{k}_{6}\right)^{1 / 2}\right]}$

As also expected, $\beta$ takes approximatively the same value as in a "pure" radiochemical environment. 
Finally, Eq. (31) leads to:

$\left[\mathrm{P}^{\bullet}\right]=\frac{2 \mathrm{k}_{6}}{\mathrm{k}_{5}}\left[\mathrm{PO}_{2}^{\bullet}\right]_{0}\left(1-\frac{\beta \mathrm{C}}{1+\beta \mathrm{C}}\right)$

i.e. $\left[\mathrm{P}^{\bullet}\right]=\frac{\left(2 \mathrm{r}_{\mathrm{i}} \mathrm{k}_{6}\right)^{1 / 2}}{\mathrm{k}_{5}}\left(1-\frac{\beta \mathrm{C}}{1+\beta \mathrm{C}}\right)$

It is now possible to integrate Eq. (20). The introduction of Eq. (33) into Eq. (20) leads to:

$\frac{\mathrm{d}[\mathrm{POOH}]}{\mathrm{dt}}=-2 \mathrm{k}_{1 \mathrm{~b}}[\mathrm{POOH}]^{2}+\mathrm{k}_{3}[\mathrm{PH}]\left(\frac{\mathrm{r}_{\mathrm{i}}}{2 \mathrm{k}_{6}}\right)^{1 / 2} \frac{\beta \mathrm{C}}{1+\beta \mathrm{C}}$

This equation can be rewritten such as:

$\frac{\mathrm{d}[\mathrm{POOH}]}{[\mathrm{POOH}]^{2}-\frac{\mathrm{k}_{3}[\mathrm{PH}]}{2 \mathrm{k}_{1 \mathrm{~b}}}\left(\frac{\mathrm{r}_{\mathrm{i}}}{2 \mathrm{k}_{6}}\right)^{1 / 2} \frac{\beta \mathrm{C}}{1+\beta \mathrm{C}}}=-2 \mathrm{k}_{1 \mathrm{~b}} \mathrm{dt}$

i.e. $\operatorname{Ln}\left\{\frac{\left(\frac{\mathrm{k}_{3}[\mathrm{PH}]}{2 \mathrm{k}_{1 \mathrm{~b}}}\left(\frac{\mathrm{r}_{\mathrm{i}}}{2 \mathrm{k}_{6}}\right)^{1 / 2} \frac{\beta \mathrm{C}}{1+\beta \mathrm{C}}\right)^{1 / 2}-[\mathrm{POOH}]}{\left(\frac{\mathrm{k}_{3}[\mathrm{PH}]}{2 \mathrm{k}_{1 \mathrm{~b}}}\left(\frac{\mathrm{r}_{\mathrm{i}}}{2 \mathrm{k}_{6}}\right)^{1 / 2} \frac{\beta \mathrm{C}}{1+\beta \mathrm{C}}\right)^{1 / 2}+[\mathrm{POOH}]}\right\}=-\mathrm{Kt}+\mathrm{a}$

i.e. $\frac{\left(\frac{\mathrm{k}_{3}[\mathrm{PH}]}{2 \mathrm{k}_{1 \mathrm{~b}}}\left(\frac{\mathrm{r}_{\mathrm{i}}}{2 \mathrm{k}_{6}}\right)^{1 / 2} \frac{\beta \mathrm{C}}{1+\beta \mathrm{C}}\right)^{1 / 2}-[\mathrm{POOH}]}{\left(\frac{\mathrm{k}_{3}[\mathrm{PH}]}{2 \mathrm{k}_{1 \mathrm{~b}}}\left(\frac{\mathrm{r}_{\mathrm{i}}}{2 \mathrm{k}_{6}}\right)^{1 / 2} \frac{\beta \mathrm{C}}{1+\beta \mathrm{C}}\right)^{1 / 2}+[\mathrm{POOH}]}=\mathrm{b} \operatorname{Exp}(-\mathrm{Kt})$

i.e. $[\mathrm{POOH}]=\left(\frac{\mathrm{k}_{3}[\mathrm{PH}]}{2 \mathrm{k}_{1 \mathrm{~b}}}\left(\frac{\mathrm{r}_{\mathrm{i}}}{2 \mathrm{k}_{6}}\right)^{1 / 2} \frac{\beta \mathrm{C}}{1+\beta \mathrm{C}}\right)^{1 / 2} \frac{1-\mathrm{b} \operatorname{Exp}(-\mathrm{Kt})}{1+\mathrm{b} \operatorname{Exp}(-\mathrm{Kt})}$

where $\mathrm{a}$ and $\mathrm{b}$ are constants to be determined from boundary conditions, and $\mathrm{K}$ is a first-order rate constant expressed by:

$\mathrm{K}=2\left(2 \mathrm{k}_{3}[\mathrm{PH}] \mathrm{k}_{1 \mathrm{~b}}\left(\frac{\mathrm{r}_{\mathrm{i}}}{2 \mathrm{k}_{6}}\right)^{1 / 2} \frac{\beta \mathrm{C}}{1+\beta \mathrm{C}}\right)^{1 / 2}$

Imposing initial conditions (i.e. $[\mathrm{POOH}]=[\mathrm{POOH}]_{0}$ when $\mathrm{t}=0$ ) to Eq. (43) gives finally:

$[\mathrm{POOH}]=[\mathrm{POOH}]_{\infty} \frac{1-\mathrm{b} \operatorname{Exp}(-\mathrm{Kt})}{1+\mathrm{b} \operatorname{Exp}(-\mathrm{Kt})}$

with $[\mathrm{POOH}]_{\infty}=\left(\frac{\mathrm{k}_{3}[\mathrm{PH}]}{2 \mathrm{k}_{1 \mathrm{~b}}}\left(\frac{\mathrm{r}_{\mathrm{i}}}{2 \mathrm{k}_{6}}\right)^{1 / 2} \frac{\beta \mathrm{C}}{1+\beta \mathrm{C}}\right)^{1 / 2}$

and $\mathrm{b}=\frac{[\mathrm{POOH}]_{\infty}-[\mathrm{POOH}]_{0}}{[\mathrm{POOH}]_{\infty}+[\mathrm{POOH}]_{0}}$

For weakly pre-oxidized samples, $[\mathrm{POOH}]_{\infty} \gg[\mathrm{POOH}]_{0}$. Experimental measurements $[28,37]$ show that: $[\mathrm{POOH}]_{\infty}>10[\mathrm{POOH}]_{0}$, therefore it can be reasonably considered that: $\mathrm{b} \approx 1$.

According to Eq. (45), triggering thermal initiation will completely slows down hydroperoxide build-up during the exposure to finally lead to a maximum concentration of hydroperoxides $[\mathrm{POOH}]_{\infty}$, in the same way as for "pure" thermal oxidation [41]. If this is really the case, it would be interesting to consider this asymptotic value in order to define a more relevant end-of-life criterion in this study, given that this latter now depends on all the exposure conditions (i.e. $\gamma$ irradiation dose rate, temperature, and oxygen partial pressure).

\subsection{Calculation of physico-chemical properties}

From these analytical solutions for $[\mathrm{POOH}],\left[\mathrm{PO}_{2}^{\bullet}\right]$, and $\left[\mathrm{P}^{\bullet}\right]$, it is now possible to calculate several key physico-chemical properties, from a practical point of view, because these properties can be checked experimentally. Undoubtedly, hydroperoxide concentration $[\mathrm{POOH}]$ and oxygen consumption $\mathrm{Q}$ are the most relevant properties because their mathematical expressions can be derived from the radio-thermal oxidation mechanistic scheme without using any additional adjustable parameter.

Recall that the rate of oxygen consumption writes:

$\mathrm{r}(\mathrm{C})=-\frac{\mathrm{d}\left[\mathrm{O}_{2}\right]}{\mathrm{dt}}=\mathrm{k}_{2} \mathrm{C}\left[\mathrm{P}^{\bullet}\right]-\mathrm{k}_{6}\left[\mathrm{PO}_{2}^{\bullet}\right]^{2}$

i.e. $r(C)=\frac{2 k_{6} k_{2} C}{k_{5}}\left(\left[\mathrm{PO}_{2}^{\bullet}\right]_{0}-\left[\mathrm{PO}_{2}^{\bullet}\right]\right)-\mathrm{k}_{6}\left[\mathrm{PO}_{2}^{\bullet}\right]^{2}$

i.e. $r(C)=k_{3}[P H]\left(\frac{r_{i}}{2 k_{6}}\right)^{1 / 2} \frac{\beta C}{1+\beta C}+r_{i} \frac{\beta C}{1+\beta C}\left(1-\frac{\beta C}{2(1+\beta C)}\right)$

It can be easily checked that, when $\beta C \gg 1$, Eq. (50) leads to the expression of the rate of oxygen consumption in oxygen excess [1]:

$\mathrm{r}_{0}=\mathrm{k}_{3}[\mathrm{PH}]\left(\frac{\mathrm{r}_{\mathrm{i}}}{2 \mathrm{k}_{6}}\right)^{1 / 2}+\frac{\mathrm{r}_{\mathrm{i}}}{2}$

The integration of Eq. (50) between 0 and $t$ gives access to the concentration of oxygen consumed by the chemical reaction $\mathrm{Q}$ :

$\mathrm{Q}=\int_{0}^{\mathrm{t}} \mathrm{r}(\mathrm{C}) \mathrm{dt}$

i.e. $\mathrm{Q}=\left[\mathrm{k}_{3}[\mathrm{PH}]\left(\frac{\mathrm{r}_{\mathrm{i}}}{2 \mathrm{k}_{6}}\right)^{1 / 2} \frac{\beta \mathrm{C}}{1+\beta \mathrm{C}}+\mathrm{r}_{\mathrm{i}} \frac{\beta \mathrm{C}}{1+\beta \mathrm{C}}\left(1-\frac{\beta \mathrm{C}}{2(1+\beta \mathrm{C})}\right)\right] \mathrm{t}$

Other key physico-chemical property in the literature are the concentrations of carbonyl products $[\mathrm{P}=0]$ and chain scissions $\mathrm{S}$. In the radio-thermal oxidation mechanistic scheme, carbonyl products can only be formed in thermal initiation (1T) and termination (6) through specific chemical events (e.g. $\beta$ scission, disproportionation, etc.) which generally compete with many other chemical events, in particular with hydrogen abstraction which gives alcohols. Consequently, the calculation of the formation rate of these oxidation products requires the use of adjustable parameters:

$\frac{\mathrm{d}[\mathrm{P}=\mathrm{O}]}{\mathrm{dt}}=\gamma_{1 \mathrm{co}} \mathrm{k}_{1 \mathrm{~b}}[\mathrm{POOH}]^{2}+\gamma_{6 \mathrm{CO}} \mathrm{k}_{6}\left[\mathrm{PO}_{2}^{\circ}\right]^{2}$

where $\gamma_{1 \text { co }}$ and $\gamma_{6 \mathrm{co}}$ are the respective formation yields of carbonyl products in thermal initiation (1T) and termination (6), see section 3.1.

If replacing $[\mathrm{POOH}]$ and $\left[\mathrm{PO}_{2}^{\bullet}\right]$ by their analytical solutions in Eq. (54), it comes:

$$
\begin{aligned}
\frac{\mathrm{d}[\mathrm{P}=\mathrm{O}]}{\mathrm{dt}}= & \gamma_{1 \mathrm{CO}} \mathrm{k}_{1 \mathrm{~b}}[\mathrm{POOH}]_{\infty}^{2}\left(\frac{1-\mathrm{b} \operatorname{Exp}(-\mathrm{Kt})}{1+\mathrm{b} \operatorname{Exp}(-\mathrm{Kt})}\right)^{2} \\
& +\gamma_{6 \mathrm{co}} \frac{\mathrm{r}_{\mathrm{i}}}{2}\left(\frac{\beta \mathrm{C}}{1+\beta \mathrm{C}}\right)^{2}
\end{aligned}
$$

$$
\text { i.e. } \begin{aligned}
\frac{\mathrm{d}[\mathrm{P}=0]}{\mathrm{dt}}= & \gamma_{1 \mathrm{co}} \frac{\mathrm{k}_{3}[\mathrm{PH}]}{2}\left(\frac{\mathrm{r}_{\mathrm{i}}}{2 \mathrm{k}_{6}}\right)^{1 / 2} \frac{\beta \mathrm{C}}{1+\beta \mathrm{C}}\left(\frac{1-\mathrm{b} \operatorname{Exp}(-\mathrm{Kt})}{1+\mathrm{b} \operatorname{Exp}(-\mathrm{Kt})}\right)^{2} \\
& +\gamma_{6} \operatorname{co} \frac{\mathrm{r}_{\mathrm{i}}}{2}\left(\frac{\beta \mathrm{C}}{1+\beta \mathrm{C}}\right)^{2}
\end{aligned}
$$




$$
\begin{aligned}
& \text { i.e. } \frac{\mathrm{d}[\mathrm{P}=\mathrm{O}]}{\mathrm{dt}}=\gamma_{1 \mathrm{CO}} \frac{\mathrm{k}_{3}[\mathrm{PH}]}{2}\left(\frac{\mathrm{r}_{\mathrm{i}}}{2 \mathrm{k}_{6}}\right)^{1 / 2} \frac{\beta \mathrm{C}}{1+\beta \mathrm{C}} \\
& +\gamma_{6 \mathrm{CO}} \frac{\mathrm{r}_{\mathrm{i}}}{2}\left(\frac{\beta \mathrm{C}}{1+\beta \mathrm{C}}\right)^{2}-\gamma_{1 \mathrm{CO}} \mathrm{k}_{3}[\mathrm{PH}]\left(\frac{\mathrm{r}_{\mathrm{i}}}{2 \mathrm{k}_{6}}\right)^{1 / 2} \\
& \times \frac{\beta \mathrm{C}}{1+\beta \mathrm{C}} \frac{2 \mathrm{~b} \operatorname{Exp}(-\mathrm{Kt})}{(1+\mathrm{b} \operatorname{Exp}(-\mathrm{Kt}))^{2}}
\end{aligned}
$$

The integration of Eq. (57) between 0 and $t$ leads finally to:

$$
\begin{aligned}
{[\mathrm{P}=\mathrm{O}]=} & {\left[\gamma_{1 \mathrm{CO}} \frac{\mathrm{k}_{3}[\mathrm{PH}]}{2}\left(\frac{\mathrm{r}_{\mathrm{i}}}{2 \mathrm{k}_{6}}\right)^{1 / 2} \frac{\beta \mathrm{C}}{1+\beta \mathrm{C}}+\gamma_{6 \operatorname{co}} \frac{\mathrm{r}_{\mathrm{i}}}{2}\left(\frac{\beta \mathrm{C}}{1+\beta \mathrm{C}}\right)^{2}\right] \mathrm{t} } \\
& +2 \gamma_{1 \mathrm{CO}} \frac{\mathrm{k}_{3}[\mathrm{PH}]}{\mathrm{K}}\left(\frac{\mathrm{r}_{\mathrm{i}}}{2 \mathrm{k}_{6}}\right)^{1 / 2} \frac{\beta \mathrm{C}}{1+\beta \mathrm{C}} \\
& \times\left(\frac{1}{1+\mathrm{b} \operatorname{Exp}(-\mathrm{Kt})}-\frac{1}{1+\mathrm{b}}\right)
\end{aligned}
$$

Similarly, chain scissions can only be formed in thermal initiation (1T) and termination (6) through $\beta$ scissions. Consequently, their mathematical expressions are identical in form to those previously established for carbonyl products, only their formation yields are different:

$$
\begin{aligned}
\frac{\mathrm{dS}}{\mathrm{dt}}=\gamma_{1 \mathrm{~S}} \mathrm{k}_{1 \mathrm{~b}}[\mathrm{POOH}]^{2}+\gamma_{6 S} \mathrm{k}_{6}\left[\mathrm{PO}_{2}^{*}\right]^{2} & \begin{aligned}
\text { i.e. } \frac{\mathrm{dS}}{\mathrm{dt}}= & \gamma_{1 \mathrm{~S}} \frac{\mathrm{k}_{3}[\mathrm{PH}]}{2}\left(\frac{\mathrm{r}_{\mathrm{i}}}{2 \mathrm{k}_{6}}\right)^{1 / 2} \frac{\beta \mathrm{C}}{1+\beta \mathrm{C}}+\gamma_{6 S} \frac{\mathrm{r}_{\mathrm{i}}}{2}\left(\frac{\beta \mathrm{C}}{1+\beta \mathrm{C}}\right)^{2} \\
& \quad-\gamma_{1 \mathrm{~s}} \mathrm{k}_{3}[\mathrm{PH}]\left(\frac{\mathrm{r}_{\mathrm{i}}}{2 \mathrm{k}_{6}}\right)^{1 / 2} \frac{\beta \mathrm{C}}{1+\beta \mathrm{C}} \frac{2 \mathrm{~b} \operatorname{Exp}(-\mathrm{Kt})}{(1+\mathrm{b} \operatorname{Exp}(-\mathrm{Kt}))^{2}}
\end{aligned}
\end{aligned}
$$

and

$$
\begin{aligned}
\mathrm{S}= & {\left[\gamma_{1 \mathrm{~s}} \frac{\mathrm{k}_{3}[\mathrm{PH}]}{2}\left(\frac{\mathrm{r}_{\mathrm{i}}}{2 \mathrm{k}_{6}}\right)^{1 / 2} \frac{\beta \mathrm{C}}{1+\beta \mathrm{C}}+\gamma_{6 \mathrm{~S}} \frac{\mathrm{r}_{\mathrm{i}}}{2}\left(\frac{\beta \mathrm{C}}{1+\beta \mathrm{C}}\right)^{2}\right] \mathrm{t} } \\
& +2 \gamma_{1 \mathrm{~S}} \frac{\mathrm{k}_{3}[\mathrm{PH}]}{\mathrm{K}}\left(\frac{\mathrm{r}_{\mathrm{i}}}{2 \mathrm{k}_{6}}\right)^{1 / 2} \frac{\beta \mathrm{C}}{1+\beta \mathrm{C}}\left(\frac{1}{1+\mathrm{b} \operatorname{Exp}(-\mathrm{Kt})}-\frac{1}{1+\mathrm{b}}\right)
\end{aligned}
$$

where $\gamma_{1 S}$ and $\gamma_{65}$ are the respective yields of chain scissions in thermal initiation (1T) and termination (6), see section 3.1.

In the case of PE oxidation, it is clear that embrittlement results essentially from chain scissions $[18,19]$. Neglecting, in a first approach, an eventual chemical cross-linking process, the changes in the concentration of elastically active chains in Si-XLPE throughout the exposure can simply be calculated as follows [42]:

$v=v_{0}-\mathrm{S}$

where $v_{0}$ and $v$ are the respective concentrations of elastically active chains before and after radio-thermal ageing. Swelling measurements and rheometry in solid state (DMTA) allowed showing that $v_{0}=0.12 \pm 0.02 \mathrm{~mol}^{-\mathrm{L}^{-1}}$ for Si-XLPE.

\subsection{Lifetime prediction}

Embrittlement is expected to occur at very low conversion ratio of the chain scission process. On one side, the corresponding critical ratio $\mathrm{S}_{\mathrm{F}}$ is related through Eq. (62) to a critical concentration of elastically active chains $\nu_{\mathrm{F}}$ to be determined experimentally. On the other side, as explained at the end of section $3.2, \mathrm{~S}_{\mathrm{F}}$ would also be related to a critical hydroperoxide concentration $[\mathrm{POOH}]_{\mathrm{F}}$ corresponding to the onset of the rapid auto-acceleration of the oxidation reaction when triggering thermal initiation. As shown in a previous publication [2], the definition of this last structural endof-life criterion is quite simple:

$[\mathrm{POOH}]_{\mathrm{F}}=\frac{[\mathrm{POOH}]_{\infty}}{\mathrm{q}}$

where $\mathrm{q}$ is an arbitrary criterion, higher than unity but not so far, to be determined experimentally.

In a first approach, it was decided to use $[\mathrm{POOH}]_{\mathrm{F}}$ for predicting the lifetime $t_{\mathrm{F}}$ of the insulating material. It was thus assumed that $\mathrm{t}=\mathrm{t}_{\mathrm{F}}$ when $[\mathrm{POOH}]=[\mathrm{POOH}]_{\mathrm{F}}$.

In this case, introducing Eq. (63) into Eq. (45) leads to:

$\mathrm{q}=\frac{1+\mathrm{b} \operatorname{Exp}\left(-\mathrm{Kt}_{\mathrm{F}}\right)}{1-\mathrm{b} \operatorname{Exp}\left(-\mathrm{Kt}_{\mathrm{F}}\right)}$

i.e. $\operatorname{Exp}\left(-\mathrm{Kt}_{\mathrm{F}}\right)=\frac{\mathrm{q}-1}{\mathrm{~b}(1+\mathrm{q})}$

i.e. $\mathrm{t}_{\mathrm{F}}=\frac{1}{\mathrm{~K}} \operatorname{Ln}\left[\frac{\mathrm{b}(1+\mathrm{q})}{\mathrm{q}-1}\right]$

\section{Results and discussion}

\subsection{Long-term behavior of PE insulating materials}

Fig. 8 shows the changes in the elongation at break $\varepsilon_{\mathrm{R}}$ of SiXLPE in air under the three dose rates under study at low temperature close to ambient. As expected, $\gamma$ irradiation induces a catastrophic embrittlement of Si-XLPE. The horizontal dashed line plotted for $\varepsilon_{\mathrm{R}}=\varepsilon_{\mathrm{F}}=50 \%$ was used to graphically determine the lifetime under these various exposure conditions. It was found that $t_{F}$ is about 30, 50, and 260 days under the highest (i.e. $400 \mathrm{~Gy} \cdot \mathrm{h}^{-1}$ ), medium (77.8 Gy.h $\left.{ }^{-1}\right)$, and lowest dose rates $\left(8.5 \mathrm{~Gy} \cdot \mathrm{h}^{-1}\right)$, respectively.

These $t_{F}$ values were plotted as a function of dose rate in Fig. 9 where they compared to those previously reported in the literature for other types of PE [1]. It should be note that the $t_{F}$ value determined at $25^{\circ} \mathrm{C}$ for "pure" thermal oxidation is also plotted, but for a dose rate of $1.5 \times 10^{-10} \mathrm{~Gy} . \mathrm{s}^{-1}$ corresponding to natural radioactivity.

The almost universal character of the long-term behavior of $\mathrm{PE}$ is confirmed. It appears to be completely independent of the chemistry (grafted with chemical group or not), macromolecular

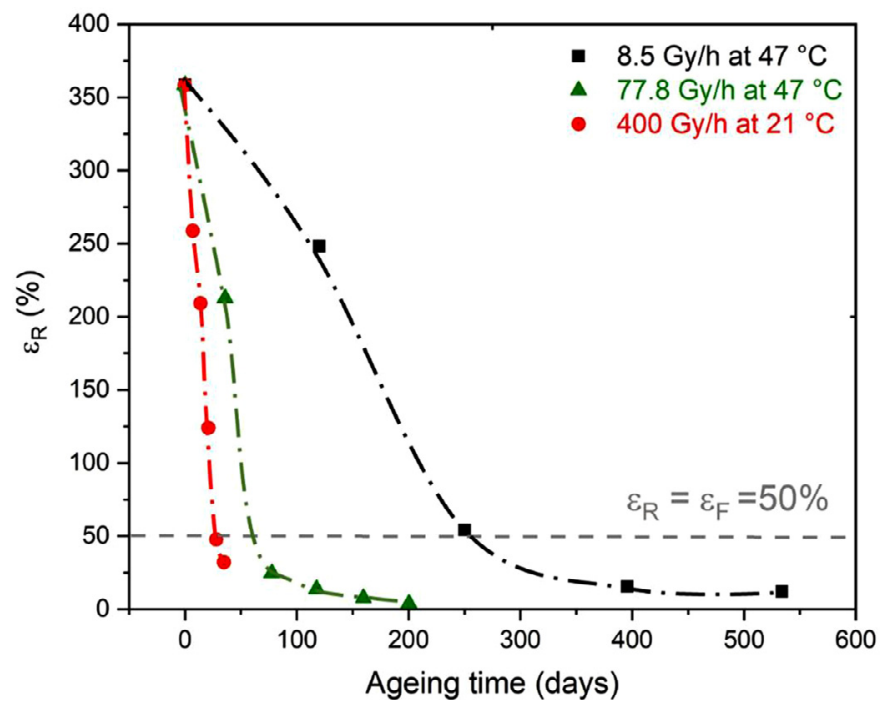

Fig. 8. Changes in the elongation at break of Si-XLPE in air under the three dose rates under study at low temperature close to ambient. 


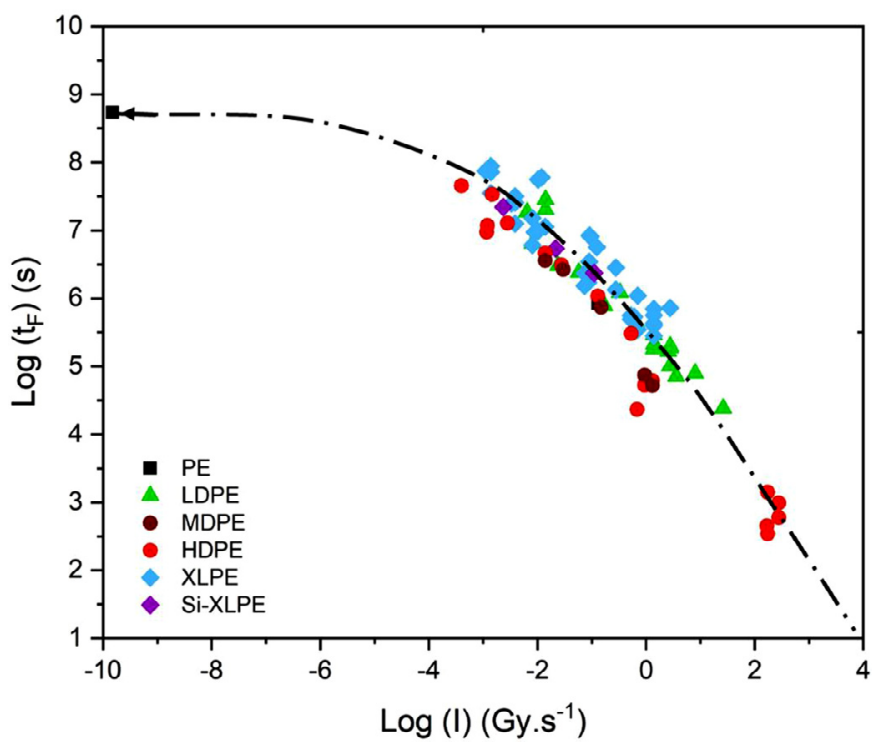

Fig. 9. Plot in logarithm co-ordinates of lifetime $t_{F}$ versus $\gamma$ dose rate $I$ in air at room temperature for unstabilised and unfilled linear PE. Comparison of the $t_{F}$ values determined for Si-XLPE in this study with those reported for various other types of linear (i.e. LDPE, MDPE and HDPE) and chemically cross-linked LDPE (i.e. XLPE) in the literature [1]. The general trend of the curve is shown using a dotted line.

Table 2

Experimental values of the lifetime and steady and critical hydroperoxide concentrations determined experimentally for Si-XLPE in air in the various radio-thermal environments under study.

\begin{tabular}{lllll}
\hline $\mathbf{I}\left(\mathbf{G y} . \mathbf{h}^{-\mathbf{1}}\right)$ & 400 & 77.8 & 8.5 & 6.0 \\
$\mathbf{T}\left({ }^{\circ} \mathbf{C}\right)$ & 21 & 47 & 47 & 86 \\
$\mathbf{t}_{\mathbf{F}}(\mathbf{d a y s})$ & 30 & 50 & 260 & - \\
{$[\mathbf{P O O H}]_{\infty}\left(\mathbf{m o l}^{-L^{-1}}\right)$} & 2.4 & $3.1 \times 10^{-1}$ & $1.7 \times 10^{-1}$ & $4.1 \times 10^{-2}$ \\
{$[\mathbf{P O O H}]_{\mathbf{F}}\left(\mathbf{m o l . L}^{-\mathbf{1}}\right)$} & $1.5 \times 10^{-1}$ & $1.8 \times 10^{-1}$ & $1.6 \times 10^{-1}$ & - \\
\hline
\end{tabular}

structure (i.e. linear, branched or chemically cross-linked) and crystallinity of PE. It can be clearly seen that all the $t_{F}$ values determined for Si-XLPE are well positioned on the master curve. In addition, these values are located in the right part of the domain of intermediary dose rates where radio-thermal oxidation proceeds. Consequently, all the physicochemical data determined in this study will be used to check the reliability of the analytical equations established in previous sections.

\subsection{Reliability of the analytical kinetic model}

In a first stage, Eqs. (45), (58), and (62) were used to respectively simulate the changes in concentration of hydroperoxides $[\mathrm{POOH}]$, carbonyls $[\mathrm{P}=\mathrm{O}]$, and elastically active chains $v$ of Si-XLPE in air under the three dose rates under study (i.e. 8.5, 77.8, and $400 \mathrm{~Gy} \cdot \mathrm{h}^{-1}$ ) at low temperature close to ambient. Simulations are reported in Fig. 10, Fig. 11, and Fig. 12, respectively. These results call for the following comments.

At short term, $[\mathrm{POOH}]$ increases with time until reaching an asymptotic value $[\mathrm{POOH}]_{\infty}$ which depends on the radio-thermal exposure conditions. All this first part of the kinetic curves is satisfyingly simulated with Eq. (45), the resulting values of $[\mathrm{POOH}]_{\infty}$ have been reported in Table 2 . As expected, $[\mathrm{POOH}]_{\infty}$ is an increasing function of irradiation dose I, but a decreasing function of temperature T. Indeed, this asymptote is the consequence of the sudden acceleration of the thermal initiation (1T), which counteracts completely the build-up of hydroperoxides formed in the propagation step of the oxidation reaction.

At longer term, for certain radio-thermal exposure conditions (e.g. under $77.8 \mathrm{~Gy} \cdot \mathrm{h}^{-1}$ at $47^{\circ} \mathrm{C}$ ), a beginning of decrease in [POOH]

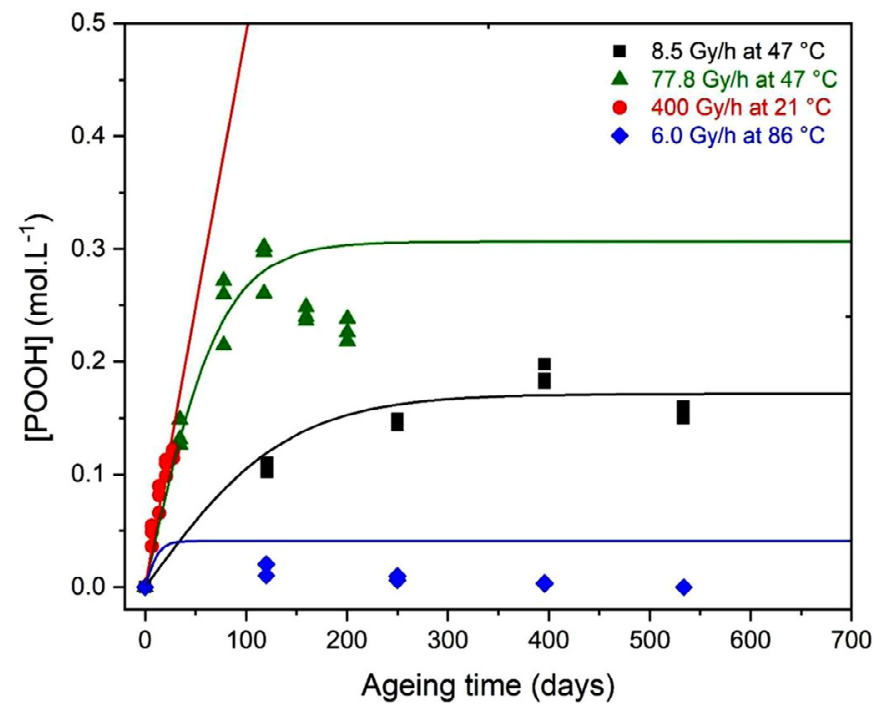

Fig. 10. Changes in the hydroperoxide concentration of XLPE in air in the various radio-thermal environments under study. Comparison between simulation with Eq. (45) (solid lines) and experimental data (symbols).

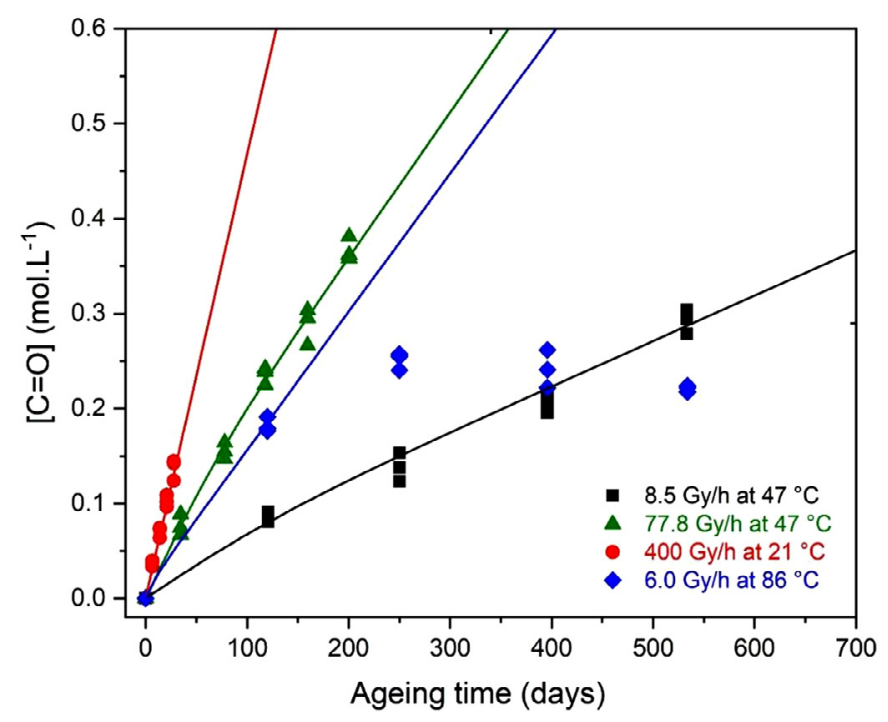

Fig. 11. Changes in the carbonyl concentration of XLPE in air in the various radio-thermal environments under study. Comparison between simulation with Eq. (58) (solid lines) and experimental data (symbols).

due to the depletion of oxidation sites $(\mathrm{PH})$ can be observed, but this second part of the kinetic curves cannot be correctly described by Eq. (45) because this latter is based on the assumption of low conversion ratios.

$[\mathrm{POOH}]_{\mathrm{F}}$ was determined graphically in Fig. 10 (i.e. when $t=t_{F}$ ) for the various radio-thermal exposure conditions under study. Its values are also reported in Table 2. It was found that $[\mathrm{POOH}]_{\mathrm{F}}$ is independent of the radio-thermal exposure conditions, which completely validates the choice of this critical quantity as structural end-of-life criterion in this study. The average value of $\approx$ $1.6 \times 10^{-1} \mathrm{mol.L^{-1 }}$ was chosen for predicting the lifetime of SiXLPE. This is exactly the same $[\mathrm{POOH}]_{\mathrm{F}}$ value that was retained in a previous publication for other types of (linear and chemically cross-linked) PE, but without making real demonstration, just based on mechanistic considerations [2].

In the early periods of exposure, $[\mathrm{P}=\mathrm{O}]$ and $v$ vary linearly with time (absence of induction period). Then, when thermal initiation gains in importance, a small loss in linearity (progressive slow- 
Table 3

Values of the kinetic parameters used for modeling the oxidation kinetics of Si-XLPE in the various radiothermal environments under study. Papers in which the same orders of magnitude were previously reported are referenced in the last column on the right.

\begin{tabular}{|c|c|c|c|c|c|}
\hline $\mathbf{T}\left({ }^{\circ} \mathrm{C}\right)$ & 21 & 47 & 47 & 86 & \\
\hline I $\left(G y \cdot h^{-1}\right)$ & 400 & 77.8 & 8.5 & 6.0 & References \\
\hline $\mathbf{G}_{\mathbf{i}}$ & 8 & 8 & 8 & 8 & {$[1,2,39]$} \\
\hline $\mathrm{k}_{1 \mathrm{~b}}\left(\mathrm{~L} \cdot \mathrm{mol}^{-1} \cdot \mathrm{s}^{-1}\right)$ & $5.0 \times 10^{-9}$ & $2.5 \times 10^{-7}$ & $2.4 \times 10^{-7}$ & $1.0 \times 10^{-5}$ & {$[2,3,20,36,39,43,44]$} \\
\hline $\mathrm{k}_{2}\left(\mathrm{~L} \cdot \mathrm{mol}^{-1} \cdot \mathrm{s}^{-1}\right)$ & $10^{8}$ & $10^{8}$ & $10^{8}$ & $10^{8}$ & {$[2,3,20,36,39,43,44]$} \\
\hline $\mathrm{k}_{3}\left(\mathrm{~L} \mathrm{~mol}^{-1} \cdot \mathrm{s}^{-1}\right)$ & $1.6 \times 10^{-3}$ & $1.9 \times 10^{-2}$ & $1.9 \times 10^{-2}$ & $3.6 \times 10^{-1}$ & {$[2,3,20,36,39,43,44]$} \\
\hline $\mathrm{k}_{4}\left(\mathrm{~L} \mathrm{~mol}^{-1} \cdot \mathrm{s}^{-1}\right)$ & $8.0 \times 10^{11}$ & $8.0 \times 10^{11}$ & $8.0 \times 10^{11}$ & $8.0 \times 10^{11}$ & {$[2,3,20,43,44]$} \\
\hline$k_{5}\left(L^{\prime} \mathrm{mol}^{-1} \cdot s^{-1}\right)$ & $1.2 \times 10^{10}$ & $7.0 \times 10^{10}$ & $9.0 \times 10^{10}$ & $2.4 \times 10^{11}$ & This study \\
\hline $\mathrm{k}_{6}\left(\mathrm{~L} \cdot \mathrm{mol}^{-1} \cdot \mathrm{s}^{-1}\right)$ & $5.0 \times 10^{4}$ & $1.0 \times 10^{6}$ & $2.0 \times 10^{6}$ & $6.0 \times 10^{7}$ & {$[2,3,20,36,39,43,44]$} \\
\hline$\gamma_{1 \mathrm{~s}}(\%)$ & 90 & 42 & 52 & 51 & {$[20,43,44]$} \\
\hline$\gamma_{6 s}(\%)$ & 90 & 42 & 52 & 51 & {$[20,43,44]$} \\
\hline$\gamma_{1 \mathrm{co}}(\%)$ & 90 & 70 & 75 & 100 & {$[20,43,44]$} \\
\hline$\gamma_{6 c 0}(\%)$ & 90 & 70 & 75 & 100 & {$[20,43,44]$} \\
\hline
\end{tabular}

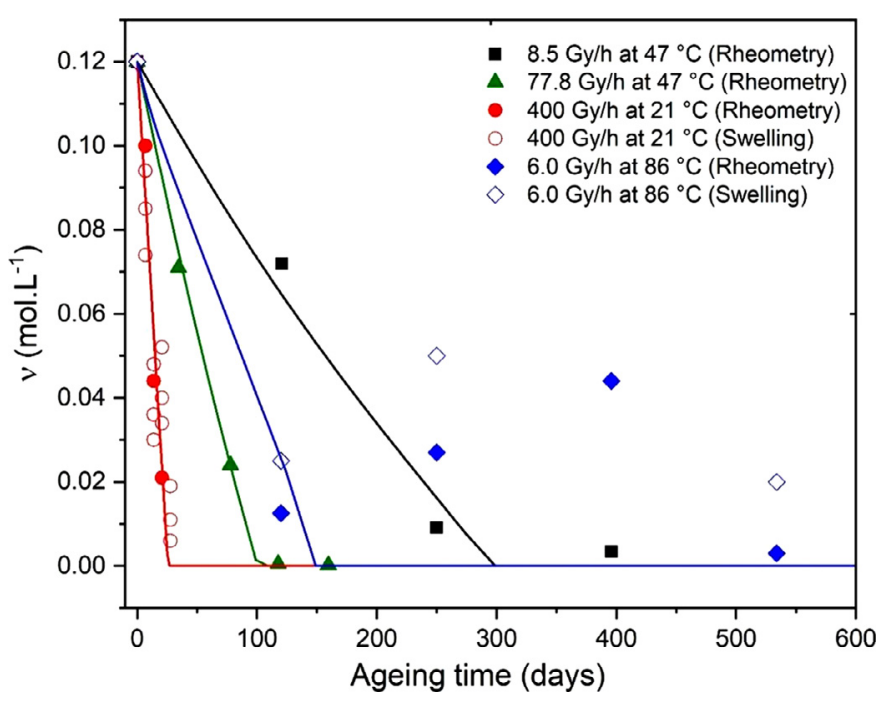

Fig. 12. Changes in the concentration of elastically active chains of XLPE in air in the various radio-thermal environments under study. Comparison between simulation with Eq. (62) (solid lines) and experimental data determined by swelling (solid symbols) and rheometry (empty symbols).

down) can be observed for both physico-chemical quantities. The whole kinetic curves are satisfyingly simulated with Eqs. (58) and (62), respectively.

In a second stage, Eqs. (45), (58), and (62) were used to respectively simulate the physico-chemical changes of Si-XLPE in air under $6.0 \mathrm{~Gy} \cdot \mathrm{h}^{-1}$ at $86^{\circ} \mathrm{C}$. Simulations are also reported in Fig. 10, Fig. 11, and Fig. 12, respectively. It can be clearly seen that the impact of the thermal initiation on the global oxidation kinetics is much more important at $86^{\circ} \mathrm{C}$ than at $47^{\circ} \mathrm{C}$. Unfortunately, the three analytical equations are not able to accurately account for the whole kinetic curves, presumably due to the starting assumption, which was deduced from Eq. (22). In order to reach this goal, it would be necessary to take into account that thermal initiation could be of the same order of magnitude as (if not greater than) radiochemical initiation. This further kinetic analysis will be the subject of a future publication. At this stage of investigations, it can be seen that the three analytical equations allow accounting for the general trends of the oxidation kinetics under these critical exposure conditions (i.e. under low dose rate at moderate temperature) where, obviously, a stronger coupling between radiochemical and thermal oxidations operates.

The values of the kinetic parameters used for all these simulations, i.e. radiochemical yield $G_{i}$, rate constants $k_{j}$ (with $j=1, \ldots$, $6)$ and the formation yields $\gamma_{1 \mathrm{co}}$ and $\gamma_{6 \mathrm{co}}$ of carbonyls products,
Table 4

Values of the rate constant $\mathrm{K}$ and criterion $\mathrm{q}$ used for predicting the lifetime of Si-XLPE in air under the three dose rates under study at low temperature close to ambient.

\begin{tabular}{llll}
\hline $\mathbf{I}\left(\mathbf{G y} \cdot \mathbf{h}^{-\mathbf{1}}\right)$ & 400 & 77.8 & 8.5 \\
\hline $\mathbf{T}\left({ }^{\circ} \mathbf{C}\right)$ & 21 & 47 & 47 \\
$\mathbf{K}\left(\mathbf{s}^{-\mathbf{1}}\right)$ & $4.8 \times 10^{-8}$ & $3.1 \times 10^{-7}$ & $1.6 \times 10^{-7}$ \\
$\mathbf{q}$ & 15.0 & 1.9 & 1.1 \\
$\mathbf{t}_{\mathbf{F}}$ (days) & 32 & 43 & 246 \\
\hline
\end{tabular}

and $\gamma_{1 S}$ and $\gamma_{6 S}$ of chain scissions, have been reported in Table 3. These values call for the following comments.

The orders of magnitude previously determined on linear PE (i.e. LDPE, MDPE and HDPE) for almost all these kinetic parameters were kept for these simulations [1-3,20,36,39,43,44]. Only $k_{5}$ was slightly reduced at low temperature close to ambient (i.e. at 47 and $21^{\circ} \mathrm{C}$ ) because it had already been proposed to allocate a small activation energy to this termination rate constant in order to better simulate the oxidation kinetics initiated by chlorine disinfectants in PE pipes carrying drinking water at ambient temperature $[20,43,44]$. Thus, the importance of this activation energy is completely checked in this study. In addition, if considering all the $k_{5}$ values published to date for PE $[2,3,20,43,44]$, it is found that its activation energy would be around $14 \mathrm{~kJ} \cdot \mathrm{mol}^{-1}$.

As there was no notable change in the values of all the kinetic parameters, it can be concluded that the reliability of the analytical kinetic model was checked in this study. Its great heuristic value has been demonstrated in Fig. 10, Fig. 11, and Fig. 12, even if some improvements are still possible, in particular at the highest temperature $\left(86^{\circ} \mathrm{C}\right)$.

The last stage of this study was to check the reliability of the last Eq. (66). Rate constant $\mathrm{K}$ and criterion $\mathrm{q}$ were determined with Eq. (44) and (63), respectively. Then, their values were introduced into Eq. (66) in order to predict the lifetime $t_{F}$ of Si-XLPE in air under the three dose rates under study at low temperature close to ambient. The resulting $t_{F}$ values are reported in Table 4 . It can been seen that they are of the same order of magnitude than those determined experimentally, thus confirming in turn the great heuristic value of Eq. (66).

\section{Conclusion}

A new analytical model was developed for predicting the radiothermal oxidation kinetics and the lifetime of electric cable insulations made of unfilled and unstabilised Si-XLPE in nuclear power plants. This model was derived from a mechanistic scheme in which the oxidation reaction is initiated both by the polymer radiolysis and the thermal decomposition of hydroperoxides, with- 
out making the usual assumption of thermal stability of hydroperoxides. After an initial period where the oxidation kinetics occurs with a constant rate, this model allows also predicting the autoacceleration of the oxidation kinetics when hydroperoxide decomposition is no longer negligible. A structural end-of-life criterion: $[\mathrm{POOH}]_{\mathrm{F}} \approx 1.6 \times 10^{-1} \mathrm{~mol}$. $\mathrm{L}^{-1}$, corresponding to the onset of this auto-acceleration, was proposed for predicting the lifetime of $\mathrm{Si}$ XLPE in the various radio-thermal environments under study.

A satisfying agreement was obtained between theory and experiments as long as thermal initiation remains a secondary source of radicals relatively to radiochemical initiation, i.e. under the three dose rates under study (from 8.5 to $400 \mathrm{~Gy} \cdot \mathrm{h}^{-1}$ ) at low temperature close to ambient (i.e. 47 and $21^{\circ} \mathrm{C}$ ). However, under the lowest dose rate (i.e. $6.0 \mathrm{~Gy} \cdot \mathrm{h}^{-1}$ ) at the highest temperature $\left(86^{\circ} \mathrm{C}\right)$, the analytical model does not correctly simulate the changes in concentration of the three physico-chemical properties investigated experimentally, i.e. hydroperoxides, carbonyls products and elastically active chains. In fact, in these critical radio-thermal exposure conditions, it would be necessary to take into account that thermal initiation could be of the same order of magnitude as (if not greater than) the radiochemical initiation. This further kinetic analysis will be the subject of a future publication. The final objective will be the proposal of an analytical equation allowing to simulate the whole master curve: $t_{F}=f(I)$ reported in Fig. 9, whatever the dose rate.

However, industrial polymers are rarely used pure, in particular they contain antioxidants. That is the reason why the next longer term objective will be to extend the kinetic model to Si-XLPE stabilized by the most common families of antioxidants, namely hydroperoxide decomposers (i.e. sulphides and phosphites) and radical scavengers (i.e. hindered phenols and secondary aromatic amines). To reach this objective, the main action mechanisms of these antioxidants will be introduced into the radio-thermal oxidation mechanistic scheme in order to derive a new system of differential equations to be solved. It should be pointed out that the main role of these antioxidants is to increase the induction period. Consequently, when these latter have been completely consumed, the Si-XLPE matrix should oxidize according to almost the same kinetics and thus, the structural end-of-life criterion established in this study should remain valid for predicting its lifetime.

\section{Declaration of Competing Interest}

The authors declare that they have no known competing financial interests or personal relationships that could have appeared to influence the work reported in this paper.

\section{CRediT authorship contribution statement}

Sarah Hettal: Investigation, Writing - original draft. Sébastien Roland: Validation, Writing - review \& editing, Supervision. Konsta Sipila: Writing - review \& editing, Supervision, Project administration. Harri Joki: Investigation. Xavier Colin: Conceptualization, Methodology, Software, Validation, Writing - review \& editing, Supervision.

\section{Acknowledgments}

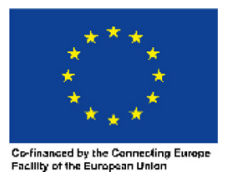

The TeaM Cables project leading to this application has received funding from the Euratom research and training program 2014-2018 under grant agreement No 755183.

\section{References}

[1] N. Khelidj, X. Colin, L. Audouin, J. Verdu, A simplified approach for the lifetime prediction of PE in nuclear environments, Nucl. Instrum. Methods Phys. Res. B236 (2005) 88-94.

[2] X. Colin, C. Monchy-Leroy, L. Audouin, J. Verdu, Lifetime prediction of polyethylene in nuclear plants, Nucl. Instrum. Methods Phys. Res. B265 (2007) 251 255.

[3] X. Colin, L. Audouin, J. Verdu, Determination of thermal oxidation rate constants by an inverse method. Application to polyethylene, Polym. Degrad. Stab. 86 (2004) 309-321.

[4] E. Niki, C. Decker, F.R. Mayo, Aging and degradation of polyolefins. -I. Peroxide-initiated oxidations of atactic polypropylene, J. Polym. Sci.: Polym. Chem. Ed. 11 (11) (1973) 2813-2845.

[5] T.C. Decker, F.R. Mayo, Aging and degradation of polyolefins. - II. $\gamma$-initiated oxidations of atactic polypropylene, J. Polym. Sci.: Polym. Chem. Ed. 11 (11) (1973) 2847-2877.

[6] C. Decker, F.R. Mayo, H. Richardson, Aging and degradation of polyolefins. -III. Polyethylene and ethylene-propylene copolymers, J. Polym. Sci.: Polym. Chem. Ed. 11 (11) (1973) 2879-2898.

[7] D.J. Carlsson, R. Brousseau, C. Zhang, D.M. Wiles, Polyolefin oxidation: Quantification of alcohol and hydroperoxide products by nitric oxide reactions, Polym. Degrad. Stab. 17 (4) (1987) 303-318.

[8] D.J. Carlsson, S. Chmela, J. Lacoste, On the structures and yields of the first peroxyl radicals in gamma-irradiated polyolefins, Macromolecules 23 (23) (1990) 4934-4938.

[9] Volume D.J. Carlsson, Degradation and stability of polymers subjected to high energy radiation, in: G. Scott (Ed.), Atmospheric oxidation and antioxidants, II, Elsevier, Amsterdam, 1993, pp. 495-528. VolumeChap. 7.

[10] K.T. Gillen, R.L. Clough, A kinetic model for predicting oxidative degradation rates in combined radiation-thermal environments, J. Polym. Sci.: Polym. Chem. Ed. 23 (1985) 2683-2707.

[11] K.T. Gillen, Importance of synergism for degradation of elastomers in combined radiation plus temperature environments, Rubber. Chem. Technol. 93 (1) (2020) 4934-4938.

[12] K.T. Gillen, H. Kudoh, Synergism of radiation and temperature in the degradation of a silicone elastomer, Polym. Degrad. Stab. 181 (2020) Article no. 109334.

[13] M. Ito, Application of chemorheology to radiation damage of polymer - III. Synergism of heat and radiation on the chemorheology of ethylene-propylene rubber, Radiat. Phys. Chem. 17 (1981) 203-205.

[14] M. Ito, Application of chemorheology to radiation damage of elastomer, Radiat. Phys. Chem. 31 (4-6) (1988) 615-621.

[15] M. Ito, Degradation of elastomer by heat and/or radiation, Nucl. Intrum. Methods Phys. Res. B265 (2007) 227-231.

[16] M. Ito, Methodology study of qualification of electric wire and cable used in nuclear power plant, in: J.W. Martin, R.A. Ryntz, J. Chin, R.A. Dickie (Eds.), Service life prediction of polymeric materials: Global perspective, Springer, New York, 2009.

[17] G. Mares, S. Ciutacu, P. Budrugeac, M. Chipara, Determination of the lifetime of ethylene-propylene rubber under the simultaneous action of heat and ionizing radiation, Polym. Degrad. Stab. 32 (1991) 31-38.

[18] B. Fayolle, X. Colin, L. Audouin, J. Verdu, Mechanism of degradation induced embrittlement in polyethylene, Polym. Degrad. Stab. 92 (2007) 231-238.

[19] B. Fayolle, E. Richaud, X. Colin, J. Verdu, Review: Degradation-induced embrittlement in semi-crystalline polymers having their amorphous phase in rubbery state, J. Mater. Sci. 43 (2008) 6999-7012.

[20] X. Colin, L. Audouin, J. Verdu, M. Rozental-Evesque, B. Rabaud, F. Martin, F. Bourgine, Aging of polyethylene pipes transporting drinking water disinfected by chlorine dioxide. -I. Chemical aspects, Polym. Eng. Sci. 49 (7) (2009) 1423-1437.

[21] A.K. Rodriguez, B. Mansoor, G. Ayoub, X. Colin, A.A. Benzerga, Effect of UV-aging on the mechanical and fracture behavior of low density polyethylene, Polym. Degrad. Stab. 180 (2020) Article no. 109185.

[22] Team Cables, Deliverable D2.2: Specifications of tests - accelerated ageing protocol, test strategy, 2018.

[23] ISO 5271:2012, Plastics - Determination of tensile properties - Part 1: General principles, 2nd edition, February 2012.

[24] ISO 5272:2012, "Plastics - Determination of tensile properties - Part 2: Test conditions for moulding and extrusion plastics, 2nd edition, February 2012.

[25] G. Geuskens, M.S. Kabamba, Photo-oxidation of polymers -Part V: A new chain scission mechanism in polyolefins, Polym. Degrad. Stab. 4 (1982) 69-76.

[26] W.D. Domke, H. Steinke, Oxidative structures in polyolefins: FTIR method of quantitative determination, J. Polym. Sci.: Polym. Chem. Ed. 24 (1986) $2701-2705$.

[27] J. Lacoste, D.J. Carlsson, Gamma-, photo-, and thermally-initiated oxidation of linear low density polyethylene: A quantitative comparison of oxidation products, J. Polym. Sci.: Polym. Chem. Ed. 30 (1992) 493-500.

[28] M.Da Cruz, L. Van Schoors, K. Benzarti, X. Colin, Thermo-oxidative degradation of additive free polyethylene - Part I: Analysis of chemical modifications at molecular and macromolecular scales, J. Appl. Polym. Sci. 133 (18) (2016) Article no. 43287.

[29] G. Rapp, J. Tireau, P.-O. Bussière, J.-M. Chenal, F. Rousset, L. Chazeau J.-L. Gardette, S. Therias, Influence of the physical state of a polymer blend on thermal ageing, Polym. Degrad. Stab. 163 (2019) 161-173. 
[30] C. Blivet, J.-F. Larché, Y. Israeli, P.-O. Bussière, J.-L. Gardette, Thermal oxidation of cross-linked PE and EPR used as insulation materials: multi-scale correlation over a wide range of temperature, Polym. Testing in press (2020) Article no. 106913.

[31] X. Colin, C. Monchy-Leroy, J. Verdu, Effect of gamma irradiation on tensile properties of low molecular weight polyethylene samples, Radiat. Phys. Chem. 80 (2011) 895-901.

[32] P.J. Flory, J. Rehner, Statistical mechanics of cross-linked polymer networks II. Swelling, J. Chem. Phys. 11 (1943) 521-526.

[33] P.J. Hendra, A.J. Peacock, H.A. Willis, The morphology of linear polyethylenes crosslinked in their melts. The structure of melt crystallized polymers in general, Polymer 28 (1987) 705-709.

[34] M. Celina, G.A. George, Characterisation and degradation studies of peroxide and silane cross-linked polyethylene, Polym. Degrad. Stab. 48 (1995) 297-312.

[35] P.J. Flory, Principles of polymer chemistry, Cornell University Press, Ithaca, 1953.

[36] N. Khelidj, X. Colin, L. Audouin, J. Verdu, C. Monchy-Leroy, V. Prunier, Oxidation of polyethylene under irradiation at low temperature and low dose rate Part II: Low temperature thermal oxidation, Polym. Degrad. Stab. 91 (7) (2006) 1598-1605.

[37] J. Huang, W. Minne, R. Drozdzak, G. Recher, P.Y. Le Gac, E. Richaud, Thermal oxidation of poly(dicyclopentadiene). Decomposition of hydroperoxides, Polym. Degrad. Stab. 174 (2020) Article no. 109102.
[38] T. Seguchi, Y. Yamamoto, Diffusion and solubility of oxygen in $\gamma$-irradiated polymer insulation materials, Japan Atomic Energy Research Institute report (1986) JAERI 1299, Takasaki, Japan.

[39] N. Khelidj, X. Colin, L. Audouin, J. Verdu, C. Monchy-Leroy, V. Prunier, Oxidation of polyethylene under irradiation at low temperature and low dose rate Part I: The case of "pure" radiochemical initiation, Polym. Degrad. Stab. 91 (7) (2006) 1593-1597.

[40] K.T. Gillen, J. Wise, R.L. Clough, General solution for the basic autoxidation scheme, Polym. Degrad. Stab. 47 (1995) 149-161.

[41] X. Colin, B. Fayolle, L. Audouin, J. Verdu, The classical kinetic model for radical chain oxidation of hydrocarbon substrates initiated by bimolecular hydroperoxide decomposition, Intern. J. Chem. Kin. 38 (11) (2006) 666-676.

[42] X. Colin, M. Ben Hassine, M. Nait-Abdelaziz, Chemo-mechanical model for predicting the lifetime of EPDM rubbers, Rubber Chem. Technol. 92 (4) (2019) $722-748$.

[43] X. Colin, L. Audouin, J. Verdu, M. Rozental-Evesque, B. Rabaud, F. Martin, F. Bourgine, Aging of polyethylene pipes transporting drinking water disinfected by chlorine dioxide. -II. Lifetime prediction, Polym. Eng. Sci. 49 (8) (2009) 1642-1652.

[44] A. Mikdam, X. Colin, G. Minard, N. Billon, R. Maurin, A kinetic model for predicting the oxidative degradation of additive free polyethylene in bleach desinfected water, Polym. Degrad. Stab. 146 (2017) 78-94. 